Discussion Paper No. 12-026

Exchange Rate Expectations of Chartists and Fundamentalists

Christian D. Dick and Lukas Menkhoff

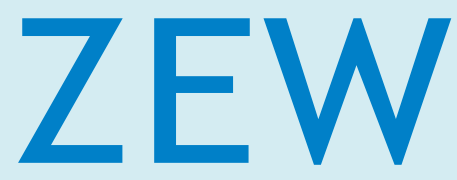

Zentrum für Europäische Wirtschaftsforschung $\mathrm{GmbH}$

Centre for European

Economic Research 
Discussion Paper No. 12-026

\title{
Exchange Rate Expectations of Chartists and Fundamentalists
}

\author{
Christian D. Dick and Lukas Menkhoff
}

Download this ZEW Discussion Paper from our ftp server:

http://ftp.zew.de/pub/zew-docs/dp/dp12026.pdf

Die Discussion Papers dienen einer möglichst schnellen Verbreitung von neueren Forschungsarbeiten des ZEW. Die Beiträge liegen in alleiniger Verantwortung der Autoren und stellen nicht notwendigerweise die Meinung des ZEW dar.

Discussion Papers are intended to make results of ZEW research promptly available to other economists in order to encourage discussion and suggestions for revisions. The authors are solely responsible for the contents which do not necessarily represent the opinion of the ZEW. 


\section{Non-technical Summary}

The present study compares exchange rate expectations of "chartists" and "fundamentalists." "Chartists" are those financial market participants who base their forecasts and actions on past price movements of their asset (here: a currency). "Fundamentalists," on the other hand, are financial market participants who base their forecasts and actions on economic models.

Various studies give empirical evidence for the presence of chartists and fundamentalists in FX markets. Expectation formation of exchange rate forecasters per se has also been studied from various perspectives in the literature. Our study, however, goes beyond previous research, as it is the first to explicitly connect the two strands of literature: how exactly do professional analysts, who claim to be either chartists or fundamentalists, make their respective exchange rate forecasts?

Our study is divided into three parts. In a first step, we analyze chartists' and fundamentalists' forecast behavior. Models including chartists and fundamentalists often make specific assumptions about these two groups. Our research can help verify these assumptions. In a second step, we model forecast dynamics caused by changes in forecasting strategies and identify the factors motivating a change in strategy. Theoretical models with chartists and fundamentalists suppose that chartists do not systematically perform worse than fundamentalists (as would be expected in efficient markets). Therefore, in a third step, we investigate forecasting performance, i.e. whether chartists' forecasts may be used as the basis for profitable trading strategies in the same manner as fundamentalists'.

In order to address this question, we combine two data sets. One is a set of micro data consisting of monthly USD/EUR forecasts made by professional analysts starting with the introduction of the Euro. Our second data set comprises information on the self-assessment of almost 400 of these professional analysts, i.e., on the degree to which they claim to rely on fundamental analysis or chart analysis to make their forecasts. The combination of the two data sets allows us to put analysts' selfassessment and their actual forecasts into context. Our panel comprises more than 30,000 observations over the course of 153 months.

Our results confirm relevant assumptions made in chartist-fundamentalist models: Chartists follow trends more often than fundamentalists and change the direction of their forecasts more often. However, there are strong influencing factors which alter both groups' forecasts, such as a great deviation from the long-term fundamental value. Also having experienced a strong trend in the past increases all forecasters' tendency to base forecasts on trends. It should finally be noted that the quality of chartists' forecasts is not inferior to that of fundamentalists' forecasts. On a short-term horizon, chartists' forecasts even appear to be more accurate than those of fundamentalists. 


\section{Nicht-technische Zusammenfassung}

Die vorliegende Untersuchung befasst sich mit den Wechselkurserwartungen von "Chartisten" und „Fundamentalisten“ im Vergleich. Als "Chartisten" bezeichnet man allgemein Finanzmarktakteure, die aus dem vergangenen Preisverlauf ihres Anlageobjektes (hier: einer Währung) Rückschlüsse für ihre Handelsentscheidungen oder Prognosen ziehen. Als „Fundamentalisten“ versteht man hingegen Finanzmarktakteure, die Handelsentscheidungen oder Prognosen auf ökonomische Modelle stützen.

Eine Reihe von Studien belegt die Präsenz von Chartisten und Fundamentalisten auf Währungsmärkten empirisch. Auch die Erwartungsbildung von Wechselkursprognosen als solche ist in der Vergangenheit verschiedentlich in der Literatur untersucht worden. Unser Beitrag geht über die bisherigen Studien hinaus, indem er die beiden genannten Literaturstränge erstmals explizit verknüpft: Wie genau formen professionelle Analysten, die sich aufgrund ihrer eigenen Angaben als Chartisten bzw. Fundamentalisten einordnen lassen, jeweils ihre Wechselkurserwartungen?

Wir gliedern unsere Untersuchung in drei Teile. In einem ersten Schritt untersuchen wir das Vorhersageverhalten von Chartisten und Fundamentalisten. Modelle mit Chartisten und Fundamentalisten treffen häufig spezifische Annahmen über diese Gruppen. Unsere Untersuchung kann dazu beitragen, diese Annahmen zu überprüfen. In einem zweiten Schritt modellieren wir die Vorhersagedynamik durch den Wechsel zwischen unterschiedlichen Prognosestrategien, und überprüfen, welche Faktoren den Wechsel begünstigen. In einem dritten Schritt untersuchen wir die Vorhersagequalität von Chartisten und Fundamentalisten. Theoretische Modelle mit Chartisten und Fundamentalisten unterstellen, dass Chartisten nicht (wie es in effizienten Märkten zu erwarten wäre) systematisch schlechter abschneiden als Fundamentalisten. Wir untersuchen deswegen, ob die Erwartungen von Chartisten gleichermaßen wie die von Fundamentalisten als Grundlage für profitable Handelsstrategien verwendet werden können.

Um dieser Fragestellung nachzugehen, verknüpfen wir zwei Datensätze: Zum einen verfügen wir über einen Mikrodatensatz mit monatlichen USD/EUR-Prognosen von professionellen Analysten seit Einführung des Euro. Zum anderen liegt uns für knapp 400 dieser Analysten eine Information darüber vor, wie stark sie -nach Selbsteinschätzung- Fundamentalanalyse bzw. Chartanalyse für ihre Wechselkursprognosen verwenden. Beide Datensätze zusammen erlauben es somit, die Selbsteinschätzung der Analysten und ihre tatsächlichen Prognosen im Kontext zu untersuchen. Insgesamt betrachten wir ein Panel von mehr als 30.000 Beobachtungen über 153 Monate.

Unsere Ergebnisse bestätigen wesentliche Annahmen, die in Chartisten-Fundamentalisten-Modellen gemacht werden: Chartisten folgen häufiger Trends als Fundamentalisten und ändern häufiger die Richtung ihrer Vorhersage. Gleichwohl gibt es starke Einflussgrößen, die die Erwartungen beider Gruppen verändern, wie etwa starke Abweichungen vom langfristigen Fundamentalwert. Auch die "Erfahrung" eines starken Trends in der Vergangenheit führt zu einer größeren Neigung aller Prognostiker, ihre Vorhersagen am Trend zu orientieren. Nicht zuletzt ist festzuhalten, dass die Qualität der Prognosen von Chartisten nicht schlechter ist als die von Fundamentalisten; auf kurze Horizonte erscheinen die Prognosen von Chartisten sogar denen von Fundamentalisten überlegen. 


\title{
EXCHANGE RATE EXPECTATIONS OF CHARTISTS AND FUNDAMENTALISTS*
}

\author{
Christian D. Dick ${ }^{\ddagger} \quad$ Lukas Menkhoff**
}

March 28, 2012

\footnotetext{
*We would like to thank participants at various seminars and workshops, in particular Agnès Bénassy-Quéré, YinWong Cheung, Oliver Gloede, Evžen Kočenda, Stefan Reitz, Jan-Christoph Rülke and Maik Schmeling for valuable comments. The paper has partly been written during a research stay of Christian D. Dick at Cass Business School, London.

${ }^{\ddagger}$ Centre for European Economic Research (ZEW) Mannheim, P.O. Box 1034 43, 68034 Mannheim, Germany, and Department of Economics, Leibniz Universität Hannover; e-mail: dick@zew.de.

${ }^{* *}$ Department of Economics, Leibniz Universität Hannover, Königsworther Platz 1, 30167 Hannover, Germany, and Centre for European Economic Research (ZEW) Mannheim, Germany; e-mail: menkhoff@gif.uni-hannover.de.
} 


\title{
EXCHANGE RATE EXPECTATIONS OF CHARTISTS AND FUNDAMENTALISTS
}

\begin{abstract}
This paper provides novel evidence on exchange rate expectations of both chartists and fundamentalists separately. These groups indeed form expectations differently. Chartists change their expectations more often; however, all professionals' expectations vary considerably as they generally follow strong exchange rate trends. In line with non-linear exchange rate-modeling, professionals expect mean reversion only if exchange rates deviate much from PPP. Chartists survive in FX markets as they forecast equally accurately as fundamentalists. Unexpected from an efficient market viewpoint, chartists even outperform fundamentalists at short horizons. Overall, these findings clearly support the chartist-fundamentalist approach.
\end{abstract}

JEL-Classification: F31, G15, D84.

Keywords: exchange rate formation, expectation formation, heterogeneous agent models, forecasting performance 


\section{Introduction}

There is ample research about the way exchange rate expectations are formed, stimulated in particular by Frankel and Froot (1987). There is also a great number of studies systematically documenting characteristics of chartists and fundamentalists in foreign exchange, starting with Taylor and Allen (1992). However, until today there has been no direct evidence combining these two strands of literature: How do professionals, who state to be chartists or fundamentalists, each form their exchange rate expectations?

This is an important question from at least three perspectives. First, the so-called chartistfundamentalist models of exchange rates make assumptions about the behavior of these two groups (e.g., Frankel and Froot, 1990; Manzan and Westerhoff, 2007; De Grauwe and Grimaldi, 2006). We examine whether chartists and fundamentalists really behave as they are assumed to do in this line of research. Second, models of heterogeneous agents have been shown to be able to replicate the characteristics of instable financial markets (Day and Huang, 1990; Farmer and Joshi, 2002). These models argue that instability arises from the expectation formation of a non-fundamentallyoriented group of traders, a notion which corresponds to our group of chartists. Hence, we examine whether the decision making of this group contributes to financial instability. Third, the existence of various groups in financial markets implicitly assumes that all these groups operate successfully in the long run. The efficient market hypothesis has stated in this respect that chartism-inspired behavior will not be competitive in the longer run (Fama, 1991). To complement the abundance of studies testing the profitability of hypothetical chartist trading rules (e.g., Park and Irwin, 2007; Neely, Weller, and Ulrich, 2010), we examine whether actual expectations of chartists and fundamentalists each provide a basis for profitable trading strategies.

All examinations presented here are the first to systematically connect information about individual exchange rate expectations with the respective professionals' preferred kind of information, i.e. charts or fundamentals. This connection enables us to directly test the real world behavior 
of chartists and fundamentalists and thus to complement existing indirect evidence derived from simulation studies (e.g., Föllmer, Horst, and Kirman, 2005; Tramontana, Westerhoff, and Gardini, 2010), experiments (Sonnemans, Hommes, Tuinstra, and Van De Velden, 2004) or explanations of forecast dispersion (Jongen, Verschoor, Wolff, and Zwinkels, 2012). Our findings clearly support the common core of the chartist-fundamentalist models: forecasters who rely heavily on charts do indeed form exchange rate expectations more in line with trends than fundamentalists and they reinforce existing trends, which may destabilize foreign exchange markets. Finally, challenging the efficient market hypothesis (Fama, 1991, 1998), chartist behavior is individually rational as these forecasts are at least as good as those of the peer group.

This study rests on the Financial Market Survey conducted on a monthly basis by the Centre for European Economic Research (ZEW) in Mannheim, Germany, among several hundred professional forecasters. This survey regularly asks professionals about their individual US-dollar / Euro expectations, starting in January 1999. We combine these answers with information about the respective individuals' self-assessment of the use of charts and fundamentals, which has been asked three times, i.e., in 2004, 2007 and 2011. Overall, our sample comprises almost 400 forecasters which provide an unbalanced panel with more than 30,000 observations over up to 153 months, until September 2011. We classify forecasters into the categories of chartists, fundamentalists, and the remaining one which we call intermediates.

Our study makes use of these data in three steps, analyzing actual forecasting behavior, forecasting dynamics and forecasting performance: (1) Regarding forecasting behavior, we test the revealed behavior of chartists and fundamentalists, as inspired by chartist-fundamentalist models. In line with earlier literature (e.g., Menkhoff and Taylor, 2007), we use the terms of charts and technical analysis as synonyms. We find that chartists tend to follow trends more frequently than fundamentalists. (2) Regarding forecasting dynamics, chartists tend to revise the direction of their exchange rate forecasts more frequently than fundamentalists, confirming a frequent assumption in heterogeneous agents' models (e.g., Brock and Hommes, 1998; Farmer and Joshi, 2002). The 
choice of forecasting tools is influenced by recent experience: when exchange rates exhibit trends, the professionals (chartists and fundamentalists) tend to switch towards chartism; in contrast, the professionals move away from chartism when the exchange rate deviates substantially from its longer-term average (the purchasing power parity, PPP). (3) Regarding forecasting performance, professionals, such as chartists, will only survive in competitive foreign exchange markets if they perform. We find that chartists are indeed equally good forecasters as fundamentalists. When differentiating between forecasting horizons chartists perform relatively better at shorter horizons, whereas fundamentalists are at least equally good at longer horizons, which nicely fits the preferred short (long) horizon of chartists (fundamentalists) (Taylor and Allen, 1992).

All these findings conform with the core assumptions of chartist-fundamentalist models or with the stylized facts about expectation formation and the use of charts and fundamentals, respectively. Detailed references to this literature are discussed in the following Section 2. In this sense, we provide supportive evidence complementing earlier approaches, which often relied on indirect tests. In detail, however, we also obtain evidence that is less conclusive with some specific assumptions. The most important issue in this respect seems to be our intuition that the switching between chartism and fundamentalism is largely an opportunistic shift of weight that forecasters give to these tools (different from De Grauwe and Grimaldi, 2006; Manzan and Westerhoff, 2007), whereas their general preferences for either charts or fundamentals seem to be quite stable over time. Moreover, chartists are neither less profitable than fundamentalists as modeled by Day and Huang (1990), nor more profitable as modeled by De Grauwe and Grimaldi (2006, p.29), and switching between strategies is not related to exchange rate volatility (ibid, p.26).

The paper is structured as follows: Section 2 briefly discusses relevant literature in order to embed our study in earlier work and to carve out our own contribution. Section 3 reports the comprehensive dataset. Section 4 presents results of our research in several steps (Sections 4.1 to 4.3), Section 5 contains robustness tests. Conclusions are provided in Section 6. 


\section{Literature and hypotheses}

This section shows the relation of our research to various strands of earlier literature, which we can cover only selectively. There are studies about exchange rate expectation formation and the use of charts and fundamentals which have heavily influenced the chartist-fundamentalist models. More generally, studies modeling the interaction of heterogeneous agents often focus on the forecasting dynamics of groups, which may lead to an instability of prices. Finally, our work is related to studies about the performance of chartist and fundamentalist trading.

Exchange rate expectation formation. In the standard economic models about exchange rate formation, representative agents perfectly understand macroeconomic fundamentals so that the present price always and fully reflects the available information. The empirical test of such models shows, however, that these stylized rational expectations models seem to be too stylized to adequately explain exchange rate formation (e.g., Meese and Rogoff, 1983; Cheung, Chinn, and Garcia-Pascual, 2005). A useful starting point to explain the existence of such a gap between models and reality is the high degree of heterogeneity among foreign exchange professionals, which has been found in seminal studies by Frankel and Froot (1990) or Ito (1990) and has later been reconfirmed by, e.g., MacDonald and Marsh (1996).

While heterogeneity as such is not a problem for models with representative agents, the heterogeneity in foreign exchange does not seem to be normally distributed. Instead, several kinds of patterns in heterogeneity have been revealed over the years, some of which are of interest for our research. In one of the first studies examining exchange rate expectations, Frankel and Froot (1987) state that the formation of exchange rates follows bandwagon expectations over short horizons and regressive expectations over longer horizons. This finding already contains the core ingredient of chartist-fundamentalist models, i.e. the co-existence of trend-following and mean-reverting expectations. This core insight has been steadily confirmed and refined in later studies (for surveys, 
see MacDonald (2000) or Jongen, Verschoor, and Wolff (2008)), e.g., by considering the fact that forecasters rely on mean-reversion in a non-linear fashion (e.g., Menkhoff, Rebitzky, and Schröder, 2008; Reitz, Rülke, and Stadtmann, 2012), an aspect we also consider in this study.

Use of charts and fundamentals. Another line of research initiated by Taylor and Allen (1992) has explicitly asked foreign exchange dealers about their use of technical and fundamental analysis when forecasting exchange rates. Dealers state that they indeed mostly use both kinds of analysis, but that they use charts at shorter horizons than fundamentals. This result has also been replicated in many studies and could be extended to fund managers (see survey by Menkhoff and Taylor, 2007).

Chartist-fundamentalist models. All this provides clear motivation to model foreign exchange markets where both, chartists and fundamentalist, co-exist and interact. An early version of such a chartist-fundamentalist model has been formulated by Frankel and Froot (1990) and has been much refined by De Grauwe and Grimaldi (2006). The basic idea is that there are two groups in the market, i.e. chartists and fundamentalists, who follow different investment strategies. Chartists usually dominate the market with their trend-following behavior, which generates its own kind of risk for fundamentalists. When, however, exchange rate misalignment becomes more and more obvious, the relative attractiveness of fundamentalism increases and more market participants follow fundamentals. This mechanism limits the power of chartism and reduces the deviation of exchange rates from their fundamental equilibrium rate; this also provides a motivation for foreign exchange interventions (e.g., Beine, De Grauwe, and Grimaldi, 2009). As long as exchange rates are not obviously misaligned such that there is less certainty about their true fundamental rate, chartists are relatively stronger. It should be noted that De Grauwe and Grimaldi (2006) define chartists as being ignorant of fundamental information. In contrast, Manzan and Westerhoff (2007) assume, for instance, that both groups are equally informed about fundamental information, but that only chartists consider technical analysis to also be relevant, whereas fundamentalists do not. 
We use the results discussed so far as guiding hypotheses for our research. Complementing earlier evidence, we demonstrate that the professional forecasters' self-assessment regarding their forecasting tools enables us to classify them as chartists, fundamentalists, or intermediates.

Next, we test whether chartists' and fundamentalists' forecasting behavior does differ as expected. As a common core chartist-fundamentalist models often assume that chartists base their forecasts on prevailing market trends by following these trends. In reality, however, there is a large variety of ways to construct a technical trading rule (see, e.g. Neely and Weller, 2011) so that the focus on trend-following strategies is less than obvious. As a consequence, we investigate whether chartists can in fact be characterized by a strong use of trend-following strategies which is, in particular, stronger than for fundamentalists (Hypothesis 1). In order to quantify trend-following we rely on simple momentum rules, although we acknowledge that trend-extrapolation could be done in more sophisticated ways in reality, as experimental evidence suggests (Rötheli, 2011).

The characterization of chartists needs to be complemented by a characterization of fundamentalists. Fundamental models basically assume a mean reverting forecasting behavior, such that a long-run moving average indicating purchasing power parity provides the hypothetical mean. Thus, we investigate whether the orientation at PPP is more pronounced for fundamentalists ( $H y$ pothesis 2). This hypothesis has been tested in a related fashion for an earlier sample of the ZEW data with a supportive result (Menkhoff, Rebitzky, and Schröder, 2008). However, this earlier paper has only used information about the use of more or less fundamental information, but did not examine chartists as an own category in comparison.

Heterogeneous agents' models. A core element of chartist-fundamentalist models in foreign exchange is the dynamics between groups. Several mechanisms have been suggested for these dynamics in the heterogeneous agents' literature. Some models rely on segmented investors, such as sophisticated $\alpha$-investors and purely trend-following $\beta$-investors introduced by Day and Huang (1990), such as Chiarella, Dieci, and Gardini (2002), or segmented markets, such as in Wester- 
hoff (2004). The results of these simulation studies are largely consistent with highly stylized facts of financial markets and observations in experimental asset markets, where, usually, students form expectations about future asset prices and operate in a dynamic market setting (see, e.g., Sonnemans, Hommes, Tuinstra, and Van De Velden, 2004; Haruvy, Lahav, and Noussair, 2007; Bloomfield, Tayler, and Zhou, 2009; Hommes, 2011). Results are also consistent with models from behavioral finance, such as Barberis, Shleifer, and Vishny (1998), where investors believe in two states of the world, i.e. a trend regime and a mean-reverting regime. Finally, heterogeneous agents have been linked to the dispersion of expectations in foreign exchange. Menkhoff, Rebitzky, and Schröder (2009) demonstrate in a somewhat abstract framework that switching between chartists and fundamentalist positions may explain forecast dispersion. Jongen, Verschoor, Wolff, and Zwinkels (2012) show in more detail how the switching between a chartist, a fundamentalist and a carry trade position can explain expectation dispersion.

In particular Brock and Hommes (1997, 1998) model a switching mechanism: agents alter their strategy when they realize that an alternative strategy has performed better than their original one. In the field of exchange rate modeling, De Grauwe and Grimaldi (2006) incorporate the notion by Brock and Hommes (1997) that switching between chartists and fundamentalists occurs through the comparison of ex post profits. This has been applied to exchange rate expectations by Jongen, Verschoor, Wolff, and Zwinkels (2012). In contrast, Lux (1998) allows both the comparison of ex post profitability as well as contagion to induce switching between different trading rules. A third explanation for switching between strategies is given by Dieci and Westerhoff (2010), who assume that all traders are familiar with both technical and fundamental trading rules, and opt for one of them based on the expected future performance rather than the ex post performance. According to this view, the agents tend to move from chartist to fundamental strategies when the deviation between fundamental value and exchange rate becomes large.

These models provide further testable hypotheses. First, various heterogeneous agents' models assume that the existence of non-fundamentally-driven behavior of a group of agents introduces 
instability to the respective system, in our case the exchange rate (e.g., Brock and Hommes, 1998; Farmer and Joshi, 2002); this idea has already been formalized earlier by, e.g., DeLong, Shleifer, Summers, and Waldmann (1989), albeit in a different way. A source of instability is these agents' willingness to often switch their positions. Applied to our case, one would expect that chartists show instable behavior by switching between appreciation and depreciation expectations (motivating long and short positions in a currency) more frequently than fundamentalists (Hypothesis 3). Regarding the concrete motivation for switching, the concept by Brock and Hommes (1997) suggests that agents evaluate alternative strategies on the basis of their ex-post profitability. Accordingly, Lux (1998) and De Grauwe and Grimaldi (2006) propose that chartist trading rules are adopted when momentum trading has been profitable in the preceding period (Hypothesis 4).

In a somewhat forward-looking modification of this rule, it is often assumed that the influence of fundamentalism increases when the exchange rate deviates more clearly from its fundamental equilibrium (e.g., Bauer, De Grauwe, and Reitz, 2009). In line with recent empirical exchange rate modeling, De Grauwe and Grimaldi (2006) introduce transaction costs to incorporate a non-linear response of exchange rates to changes in fundamentals (e.g. Dumas, 1993; Taylor, Peel, and Sarno, 2001; Kilian and Taylor, 2003). This implies that a greater deviation from the fundamental value decreases the perceived risk of following a fundamental strategy, and the switching mechanism in this model induces a shift from chartist to fundamentalist strategies (Hypothesis 5).

Performance of chartist trading. Independently of these research issues, there is a continuous line of studies examining the profitability of chartist trading in foreign exchange. Profitability is a crucial issue because it justifies the existence of chartists in competitive financial markets. Since the 1970s many studies have found that simple trading rules applied to a set of exchange rates seem to generate considerable excess returns. This main result has been confirmed by later studies which extend the analysis to different forms of technical analysis and to various methodological refinements (e.g. Okunev and White, 2003; Qi and Wu, 2006; Park and Irwin, 2007; Neely, Weller, 
and Ulrich, 2010).

A shortcoming of these studies in assessing chartists' performance is that they can only analyze simulated trading rules and do not calculate real-world returns. Another shortcoming is that a comparative analysis of forecasting performance by chartists and fundamentalists has been neglected almost completely by previous empirical studies. An exception is Goodman (1979), who finds favorable results for chartists, although for a small sample. This lack of consideration in empirical research is surprising, as theoretical models disagree about whether chartists are superior or inferior to fundamentalists: earlier heterogeneous models, such as Day and Huang (1990) tend to model the non-fundamental traders in a way that they call "buy high and sell low", i.e., these traders lose money until they learn how fundamental strategies work. De Grauwe and Grimaldi (2006), in contrast, suggest that chartists are generally more profitable than fundamentalists. Ultimately, the performance of forecasts based on chartist and fundamental information as well as their profitability is an empirical issue. In functioning markets professionals should only consider useful information such that neither chartists nor fundamentalists should be systematically superior, an idea we will analyze on the basis of our data (Hypothesis 6).

However, there are two caveats to be made: first, in some analyses we seemingly reduce chartism to momentum trading which is, of course, not the same. The difference may be important in our study, because we cover the major exchange rates over the last decade, i.e. a case where earlier studies show that simple momentum trading does not work profitably (Pukthuanthong, Levich, and Thomas III, 2007; Menkhoff, Sarno, Schmeling, and Schrimpf, 2012). Second, it seems interesting to control results for the attractively high returns from carry trades (see survey by Burnside, 2011). On the one hand carry trading may be seen as a form of "chartism" in the sense of mechanically conditioning investment decisions on interest rates. On the other hand chartists may be expected to execute not only carry trades but to (also) follow different considerations.

Overall, we examine six hypotheses derived from a rich literature. The starting assumption on the existence of chartists and fundamentalists only provides the ground for our research. Hy- 
potheses 1 and 2 analyze forecasting behavior, Hypotheses 3 to 5 analyze forecasting dynamics and Hypothesis 6 addresses forecasting performance. Hypotheses 2 and 6 have been tested before with smaller samples; regrading the remaining hypotheses, our study enters new ground.

\section{Data}

We consider a unique panel of individual exchange rate forecasts made by almost 400 German professional forecasters contributing to the Financial Market Survey by the Centre for European Economic Research (ZEW) in Mannheim, Germany. Due to its length (monthly observations starting in 1991) and broadness (an average of about 300 forecasters respond each month), the database has been used for recent empirical research (e.g., Schmeling and Schrimpf, 2011).

Microdata of the USD/EUR forecast. The data are particularly interesting for our research questions as we are able to connect the forecasts to additional information on the preferred FX forecasting tools of as many as 396 of the participating professional forecasters. We are not only able to follow an individual forecaster's expectations with respect to the USD/EUR rate over time, but we are also able to link these expectations to the forecaster's stated use of fundamental analysis, technical analysis and the analysis of order flows, respectively. This kind of information has been surveyed at three different points in time, i.e. in 2004.01, 2007.04 and 2011.09, and a part of the forecasters has responded to more than one of these special surveys. For our analysis, we focus on the USD/EUR forecasts after the introduction of the Euro in 1999.01, and we generally consider only those forecasters from whom we have collected additional information on forecasting tools. Thus, we analyze a panel consisting of a total of 33,861 observations from 153 months (until 2011.09). Some robustness checks are based on the entire panel of forecasters during this time period, which comprises 744 forecasters and a total of 44,950 observations. We do not consider forecasters who have responded to the survey less than 10 times.

The exchange rate forecasts are of directional nature, i.e. we have information on whether a 
forecaster expects the USD to appreciate, remain constant or depreciate against the Euro. Each forecast is associated with a time stamp indicating the exact day on which the forecast was made. This allows us to track the circumstances (such as prevailing trends) around each forecast.

The use of charts by forecasters. The special surveys in 2004.01, 2007.04 and 2011.09 ask the forecasters to attach percentage figures to their use of fundamental analysis, technical analysis and the analysis of order flows. Table 1 summarizes the cross sectional means and standard deviations of the answers to this question.

[Table 1 about here]

The table reveals that, on average, the proportion of the analytical tools remains relatively constant. Analysts attribute an average share of almost sixty percent to fundamental analysis, and below thirty percent to technical analysis. Over the years, the importance of order flow analysis for exchange rate forecasting appears to increase slightly, although it remains minor compared to the other sources. Hence, we concentrate on fundamental and technical analysis in the remainder of this paper.

These responses can be directly compared to those reported in Menkhoff and Taylor (2007, Table 3) as the identical survey question has been applied. The foreign exchange dealers, who are also located in Germany (and Austria), give charts a weight of 35 percent to 45 percent, whereas international fund managers give a weight of 36 percent to 37 percent. These figures are markedly higher than for our sample of professional forecasters with 27 percent to 30 percent, although the difference between our analysts and the fund managers is not very large. Accordingly, the weight of fundamentals is much higher in our sample, in particular compared to dealers.

Chartists and fundamentalists. In particular, we make use of the information given in the special surveys to form groups of fundamentalists and chartists, respectively. For the choice of our groups, we take into account that most forecasters indicate to apply both fundamental and 
technical analysis for their forecasts at least to some extent, while fundamental analysis dominates in quantitative terms for the majority of forecasters. To obtain groups of forecasters with diverging forecasting techniques, we define the two groups in a pragmatic way reflecting the kind of data they use. There are two criteria forecasters need to meet in order to be classified as chartists: first, they give a relatively larger weight to technical analysis than to fundamental analysis (or order flow analysis), and second, their weight of technical analysis is at least at the 40 percent level. In order to obtain groups of similar size and thus to make the distinction clear, we define fundamentalists as forecasters who give a weight of at least 80 percent to fundamental analysis. The remaining forecasters are called intermediates, but we realize that their forecasting behavior will be largely characterized by reliance on fundamentals. For those forecasters who have responded to the special questions more than once, we compute the average response.

[Table 2 about here]

Table 2 shows that our chosen groups of forecasters represent a relatively sharp selection: only 60 and 65 forecasters are classified as chartists and fundamentalists, respectively, while the large majority of the total of 396 forecasters, i.e. 271 persons, is classified as intermediate. The fundamentalists only attach a weight of below 8 percent to chartist strategies, which is much lower than the 56 percent stated by chartists. In contrast, the group of chartists attaches an average weight of 30 percent to fundamental information, which is much lower than the fundamentalists' 89 percent. Hence, the two groups, fundamentalists and chartists, differ substantially in terms of the used forecasting methods, while the group of intermediates comprises all remaining forecasters. Overall, the data support the existence of chartists and fundamentalists, and thus the basic assumption motivating this research.

Note the asymmetry between chartists' and fundamentalists' use of the other group's forecasting technique: the group of chartists makes substantial use of fundamental information, while the group of fundamentalists does not equivalently use technical information. This result follows mainly 
from our definition of the two groups, which is asymmetric, and should not be interpreted as a particular group behavior. In this sense, these findings are consistent with Manzan and Westerhoff (2007) who postulate that both fundamentalists and chartists share fundamental information, whereas De Grauwe and Grimaldi (2006) assume that chartists do not have any insights into fundamental behavior. However, our results indicate that most professionals also believe that there is information in technical analysis, not just chartists as supposed by Manzan and Westerhoff (2007).

Persistence and representativeness. A final issue in the data section is data reliability. Since professionals are asked three times about the analytical tools they use to forecast exchange rates, we can compare each individual's persistence in answers. The respective Panels A and B in Table 3 show that the broad majority of respondents continues to use the tools they had used before. Over a period of four and a half years covered by Panel A, 91 of 135 respondents are classified on the diagonal, i.e. 67 percent stay within the same group. Even more revealing may be the fact that only 1 out of 38 chartists and fundamentalists switches positions. The numbers are slightly less advantageous over the seven-year period covered by Panel B (i.e., 62 percent and 3 out of 43). These observations strongly indicate that the classification into chartists and fundamentalists is quite persistent at the individual level, even though professionals adjust weights between their analytical tools over time.

[Table 3 about here]

Furthermore, the considered set of forecasters (those who have provided us with a self-assessment of preferred forecasting tools at the special surveys) is representative of the entire set of forecasters in terms of their predictions: as Table 4 demonstrates, the average percentage shares of the considered forecasters predicting an appreciation, no-change, or a depreciation is very similar to the respective percentage shares of all forecasters, with deviations amounting to only 1 to 1.5 percentage points. In addition, the proportions measured for our panelists on the one hand and for 
the entire set of forecasters on the other are also highly correlated $(\rho>0.95)$ when compared over time.

[Table 4 about here]

Exchange rates and inflation data. We use the USD/EUR exchange based on the exchange rate XUDLERD issued by the Bank of England with daily frequency. This time series has the advantage of also comprising a synthetically-computed exchange rate for the time before 1999.01, which we need, e.g., for the computation of long-run averages. We replace missing exchange rates (e.g. from weekends) with those recorded on the preceding trading day. When computing the profits from trading rules involving both spot and forward rates, we use data from Thomson Financial Datastream. ${ }^{1}$ Where needed, we consider the Consumer Price Index in the Eurozone and the United States obtained from Datastream. ${ }^{2}$

\section{Empirical results}

This section documents examination results about exchange rate expectations of chartists and fundamentalists in three steps. First, we show results on forecasting behavior (Section 4.1), then results on forecasting dynamics (Section 4.2) and finally results on forecasting performance (Section $4.3)$.

\subsection{Results on forecasting behavior}

We make use of the professionals' self-assessment to compare the observed behavior of chartists and fundamentalists; for each of these groups, we analyze the role of trend-following behavior as well as PPP orientation.

\footnotetext{
${ }^{1}$ Datastream Mnemonics: TDEUR1F, TDEUR2F, TDEUR6F, TDEUR1Y, TDEUR2Y, TDEUR3Y, TEUSDSP.

${ }^{2}$ Datastream Mnemonics: USCONPRCE, EMCONPRCF.
} 
Trend-following behavior. Virtually all chartist-fundamentalist models define chartists as being primarily trend-followers. In this paragraph, we investigate whether chartists' predictions tend to be more in line with trend-following strategies compared to those made by fundamentalists (see our Hypothesis 1). Our results confirm this conjecture.

In particular, we consider a set of simple momentum-based strategies according to which forecasters could extrapolate a prevailing trend (over the past 10, 30, 60, 90 and 180 days) to make a forecast. These rules predict a further appreciation (depreciation) of the USD if the USD has gained (lost) value compared to the EUR in the past DD days, i.e.

$$
E\left[\Delta s_{t, t+h}\right]=\phi^{(k, D D)} \Delta s_{t-D D, t} \text { with } \phi^{(k, D D)}>0
$$

As we know from Section 3 that chartists also use fundamental prediction tools in addition to chartist rules, it is unlikely that their forecasts correspond to those from Eq. (1) at all time. Compared to fundamentalists' predictions, however, one could still expect a higher level of association of chartists' predictions and trend-following behavior. To analyze this, we summarize the degree to which the FX forecasts of an individual forecaster $i$ are in line with chartist behavior by computing the percentage share of forecasts by forecaster $i$ made into the same direction as the forecast made according to Eq. (1), i.e.

$$
\operatorname{SHARE}_{i}^{D D}=\frac{\text { number of forecasts by } i \text { in line with trend-following strategy }}{\text { number of all forecasts by } i}
$$

where $D D$ captures the number of days for which a potential trend is measured. A share of unity indicates that a forecaster's predictions are in all time periods in line with a forecasting rule which extrapolates the trend over the previous $D D$ days. Hence, $\mathrm{SHARE}_{i}^{D D}$ represents a measure of revealed association of a forecaster's predictions with simple momentum rules, and it can be easily compared with the self-assessed preferences of forecasting tools by the respective forecaster $i$ : in this vein, Table 5 summarizes the correlation coefficients of $\operatorname{SHARE}_{i}^{D D}$ with the percentage figure 
attributed by $i$ to fundamental and technical analysis, respectively.

[Table 5 about here]

Table 5, Panel A, shows that $\operatorname{SHARE}_{i}^{D D}$ decreases with the preference for fundamental analysis, and increases with the preference for technical analysis. As the correlation coefficients decrease in absolute value for trend periods longer than 30 days, we conclude that the distinction between chartists and fundamentalists is particularly pronounced for shorter trend periods, i.e. trends which are not necessarily well explained by fundamentals. Table 6 compares the average $\mathrm{SHARE}^{D D}$ for the groups of chartists and fundamentalists.

[Table 6 about here]

Table 6, Panel A, reconfirms that the association of individual forecasts with the extrapolation of trends tends to be higher among chartists, and lower among fundamentalists. The t-test comparing these two groups indicates that this difference is significant, at least as far as the trends on a 10 , 30 or 60-day horizon are concerned. On the basis of simple technical rules, these findings overall demonstrate that revealed trend-following and the stated preference for technical analysis is closely linked. This result does not only confirm Hypothesis 1, but also ultimately underlines the credibility of the self-assessment in the special surveys.

While the results above on average hold across prevailing trends of different sizes (which also includes very small past changes in exchange rates), we also take a closer look at how the average $\mathrm{SHARE}^{30}$ evolves depending on different strengths of the trend. To do so, we sort the (absolute) 30-day trends into ten intervals according to deciles (i.e, the first interval including the periods with only little movement of exchange rates and the tenth interval including the periods with large exchange rate movements), and compute the average $\mathrm{SHARE}^{30}$ separately for each of these intervals. Figure 1 displays the results for chartists and fundamentalists, respectively.

[Figure 1 about here] 
Figure 1 illustrates that (i) forecasters are more sensitive to momentum when past exchange rate trends have been strong (we will discuss this idea in more depth in the next section) and that (ii) the group of fundamentalists behaves differently from chartists and intermediates, as they remain relatively unimpressed by momentum compared to the other groups: for chartists, $\mathrm{SHARE}^{30}$ is on average 0.35 for the lowest interval, while it is 0.51 for the highest interval. In contrast, SHARE ${ }^{30}$ only rises to 0.44 for the group of fundamentalists.

PPP orientation. The purchasing power parity is the most prominent fundamental concept in theoretical exchange rate determination, in particular at horizons of six months and longer (see Cheung and Chinn, 2001; Cheung, Chinn, and Marsh, 2004), and hence, we investigate to what extent chartists and fundamentalists make use of this idea when predicting exchange rates. We do not find that PPP orientation is more pronounced for fundamentalists (see our Hypothesis 2), but we are able to demonstrate that PPP orientation increases non-linearly with increasing fundamental misalignment.

To determine whether or not an exchange rate is in line with fundamentals, we consider the real exchange rate

$$
q_{t}=s_{t}+\ln \left(C P I_{t}^{E U R}\right)-\ln \left(C P I_{t}^{U S}\right)
$$

and compute, for each point in time $t$, the average real exchange rate $\bar{q}_{t}$ over the previous 10 years. A forecast with PPP orientation is then made on the basis of

$$
E \Delta s_{t, t+k}=\phi^{(P P P)}\left(\bar{q}_{t}-q_{t}\right) \text { with } \phi^{(P P P)}>0
$$

Similarly to the measure $\operatorname{SHARE}_{t}^{D D}$ introduced in Eq. (2), we summarize the degree to which the FX forecasts of an individual forecaster $i$ are in line with PPP orientation by computing the percentage share of forecasts made into the same direction as the forecast made by Eq. (4), i.e. 


$$
\mathrm{SHARE}_{i}^{P P P}=\frac{\text { number of forecasts by } i \text { in line with PPP orientation }}{\text { number of all forecasts by } i}
$$

Table 5 and 6 (in both tables: Panel B) inform about the relative importance of PPP orientation for the considered groups. The correlation coefficient between $\operatorname{SHARE}_{i}^{D D}$ and the stated preference for fundamental (or technical) analysis is not significantly different from zero. Moreover, on average, 33 percent of all forecasts made by chartists and fundamentalists are made into the direction which can be interpreted as being in line with PPP orientation, which does not reveal any meaningful difference between chartists and fundamentalists (see also Cheung, Chinn, and Marsh, 2004). One reason for this result may be the fact that fundamentalists consider economic fundamentals in more complex ways than assumed here for the sake of simplicity.

To see how PPP orientation differs depending on the degree of fundamental misalignment, we sort the periods of survey responses into ten intervals according to the deciles of the absolute size of $\left|\bar{q}_{t}-q_{t}\right|$, and present the averages separately for each of these intervals in Figure 2 .

[Figure 2 about here]

Figure 2 shows that the orientation at PPP $\left(\mathrm{SHARE}^{P P P}\right)$ dramatically increases from 0.33 to 0.57 (for intermediates) with increasing misalignment of interest rates. This holds qualitatively true for chartists, intermediates, and fundamentalists. For fundamentalists, this effect appears to be slightly more pronounced, as the average $\mathrm{SHARE}^{P P P}$ even increases from 0.27 to 0.63 . Overall, the steep increase of SHARE ${ }^{P P P}$ in the five upper deciles is consistent with the view of a non-linear influence of PPP on exchange rate movements (e.g., Taylor, Peel, and Sarno, 2001). The fact that all groups of forecasters exhibit similar behavior in that respect (with only a gradual difference between chartists and fundamentalists) underlines that fundamental analysis is well present in the information set of our group of chartists, a result which again reconfirms the stated preferences by this group. 


\subsection{Results on forecasting dynamics}

This section looks at changes in forecasting behavior in two ways. First, we analyze the probability of professionals to switch the direction of their exchange rate expectations. Second, we analyze transitions from chartist to fundamentalist behavior (and reverse) by studying the dynamics of the proportion of forecasts in our panel that are in line with trend-following behavior (as a measure of chartist behavior).

Forecasting instability. It is frequently believed that technical traders typically provide less stable predictions than fundamentalists (see our Hypothesis 3). Agent based models (e.g., by Brock and Hommes, 1998; Farmer and Joshi, 2002; Westerhoff, 2004) adopt this view in their modeling assumptions, such that it is typically a group of "chartists" which - due to its changes in expectations and thus trading positions - is responsible for volatility in the markets. As we discuss below in more detail, our evidence supports this idea.

We measure the switching probability of an individual forecaster by the relative frequency with which a forecaster changes the direction of his USD/EUR forecast within two subsequent survey months, i.e. we count the number of such switches from a depreciation to an appreciation expectation or inversely, and divide it by the number of total possible switches. In a cross-sectional comparison, it becomes apparent that the switching probability is negatively correlated to the stated use of fundamental information, and positively correlated to the stated use of technical information (see Table 7, Panel A).

[Table 7 about here]

In addition, Table 7, Panel B, reports the cross-sectional averages of the individual switching probabilities for chartists and fundamentalists, respectively. It shows that the individual switching probabilities are, on average, about 14 percent for chartists, but only about 9 percent for fundamentalists. 
These probability figures refer to month-to-month changes, and the impact of their difference becomes more visible when translated into probabilities of changes in an annual perspective (see Figure 3): based on a binomial distribution where $p$ equals the monthly switching probability, the probability of no change (only one change or less) in forecasts over the course of one year declines from $0.32(0.71)$ for chartists to $0.17(0.49)$ for fundamentalists. This pattern reconfirms that chartists tend to switch more frequently from a long to a short position forecast and vice versa than fundamentalists, which lends support to Hypothesis 3.

[Figure 3 about here]

Explaining the dynamics. The change of expectations may be induced by a switch of strategies, e.g by shifts from fundamental to chartist strategies or reverse. Reasons for such shifts are at the core of our Hypotheses 4 and 5. This paragraph describes the dynamics of the forecasters' alignment with trend-following forecasting.

In particular, we reconsider the chartist forecasting rule introduced by Eq. (1). Unlike in our analysis above, we now concentrate on the time series dimension and compute, for each period, the proportion of forecasts in the panel of forecasters which points into the same direction as the 30-day chartists forecasting rule, i.e.

$$
\mathrm{SHARE}_{t}^{30}=\frac{\text { number of forecasters in period } t \text { in line with trend-following strategy }}{\text { number of all forecasters in period } t}
$$

Figure 4 illustrates how this proportion fluctuates over time, separately for the groups of chartists and fundamentalists. The two graphs show that there are substantial short-term fluctuations in these proportions; it can also be seen that the dynamics are similar, albeit not identical, for chartists and fundamentalists.

[Figure 4 about here] 
In the following paragraphs, we investigate external circumstances influencing forecasters' decisions to turn to chartist forecasting rules, i.e. the factors determining changes in the proportion of forecasts in line with trend-following forecasting rules, by time series regressions of the type

$$
\Delta \mathrm{SHARE}_{t}^{30}=a_{0}+a_{1} \Delta \mathrm{SHARE}_{t-1}^{30}+a_{2} \Delta X_{t}+e_{t}
$$

$\Delta \mathrm{SHARE}_{t}^{30}$ denotes the change in the proportion of forecasts made in $t$ which point into the same direction as a trading rule following the trend over the previous 30 days, $\triangle \mathrm{SHARE}_{t-1}^{30}$ a lagged dependent variable and $\Delta X_{t}$ represents the changes in several control variables. These control variables are discussed in more detail below. Due to potential overlaps (the forecasts are made on a six-month horizon, whereas we sample at monthly frequency), we use Newey-West standard errors with a lag length of five months.

Switching due to success of past momentum strategies. Based on the framework outlined above, we test whether the proportion of forecasters who make use of trend-following strategies reacts to the past performance of such strategies (our Hypothesis 4). We find evidence in favor of this idea.

In our main operationalization, we assume that investors look back at the previous month's exchange rate movements, and interpret the presence of a strong trend as a signal for the profitability of momentum strategies (ignoring that following a momentum strategy could also lead to losses). This approach (an investment into the currency which has ex post appreciated in the previous 30 days) can be formalized by

$$
r_{t}^{\text {expost }(30)}=\left|f_{t-1}^{1}-s_{t}\right|
$$

where $f_{t-1}^{1}$ and $s_{t}$ represent the (log) forward and spot rates in $t-1$ and $t$, respectively.

We include changes in returns, i.e. $\Delta r_{t}^{\text {expost(30) }}=r_{t}^{\text {expost(30) }}-r_{t-1}^{\text {expost(30) }}$ into the regression equation (7) as a variable of interest; we refer to changes in returns between two months because 
we want to explain changes in the share of participants following trends also over two months. Given the idea of our Hypothesis 4, we expect to find significantly positive coefficients. Table 8, (i), displays the results.

[Table 8 about here]

It transpires that the coefficients for $\Delta r_{t}^{\text {expost(30) }}$ are statistically significantly positive at the one-percent significance level. The adj. $R^{2}$ amounts to 18.5 percent, which is higher than the 11.8 percent obtained by (unreported) pure $\mathrm{AR}(1)$ regressions. Hence, the inclusion of past returns adds explanatory power. This result demonstrates that forecasters indeed take into account the size of the most recent trends, and switch to chartist rules after relatively large trends. In fact, the described relationship is also economically significant: when the change in the return from holding the appreciating currency amounts to 2.1 percentage points (which corresponds to one standard deviation of $\Delta r_{t}^{\text {expost }}$ ), the percentage share of survey participants who follow chartist strategies increases by an average of 5.4 percentage points, which corresponds to 35 percent of the standard deviation of monthly changes of that proportion. Overall, forecasters tend to enter the camp of chartists directly after large trends and they do not wait another month to see whether the adoption of a momentum strategy has been profitable in the preceding period.

One caveat has to be expressed, however. For a stricter interpretation of Hypothesis 4, one could also assume that forecasters observe very closely if a past momentum strategy -which has been chosen based on the information set a period ago- has been profitable, or if it has led to losses (a possibility which we have ignored in our approach above). Here, the profitability which matters is the most recent monthly return of an investment decision which was made one month earlier according to Eq. (1) based on the trend observed at that time, i.e.,

$$
r_{t}^{T R 30}=I_{t-1}\left(s_{t-1}>E_{t-1}^{(1)}\left[s_{t}\right]\right)\left(f_{t-1}^{1}-s_{t}\right)+I_{t-1}\left(s_{t-1}<E_{t-1}^{(1)}\left[s_{t}\right]\right)\left(s_{t}-f_{t-1}^{1}\right)
$$

where $I_{t-1}$ is an indicator variable for a decision made in the previous period and $E_{t-1}^{(1)}\left[s_{t}\right]$ represents 
the forecast made on the basis of Eq. (1). When we include $\Delta r_{t}^{T R 30}=r_{t}^{T R 30}-r_{t-1}^{T R 30}$ on the RHS of Eq. (7), the coefficient for $\Delta r_{t}^{T R 30}$ is not significantly different from zero (see Table 8, (ii)). Thus, according to this result it is not the behavior described in Eq. (9) which drives forecasting dynamics. Our findings rather indicate that forecasters adopt chartist rules when the presence of trends suggests it might be profitable to follow them.

Switching due to deviations from fundamentals. Most chartist-fundamentalist models with switching behavior imply that chartist strategies become less important when exchange rates deviate substantially from fundamentals (Hypothesis 5 ). We confirm this assumption on the basis of our data; in particular, our findings corroborate the non-linearity of this relationship which is frequently included in these models.

To illustrate this point, we consider the real exchange rate to be misaligned when its deviation from the average value, i.e. $\left|q_{t}-\bar{q}_{t}\right|$ (see Eq. (3)) is high. As several exchange rate models suggest that the relationship between fundamentals and exchange rate is non-linear (Dumas, 1993; Taylor, Peel, and Sarno, 2001; Obstfeld and Rogoff, 2000), we also consider the squared distance $\left|q_{t}-\bar{q}_{t}\right|^{2}$, which gives stronger weight to observations for which the misalignments are more pronounced. In particular, in the framework of the time series regression as in Eq. (7), we analyze whether shocks to these deviations $\left(\Delta\left|q_{t}-\bar{q}_{t}\right|\right)$ or squared deviations $\left(\Delta\left|q_{t}-\bar{q}_{t}\right|^{2}\right)$ exert influence on the change of the use of chartist rules.

[Table 8 about here]

Table 8, (iii) and (iv), displays the results. The coefficient for $\Delta\left|q_{t}-\bar{q}_{t}\right|$ is negative, but not significantly different from zero, indicating that the absolute deviation between fundamental values and exchange rate rules does not affect the use of chartist rules. In contrast, the coefficient for $\Delta\left|q_{t}-\bar{q}_{t}\right|^{2}$ is significantly smaller than zero, which indicates that shocks to the deviation of exchange rates from fundamental values do matter when the deviation is substantially large. This result is 
in line with the earlier finding in Menkhoff, Rebitzky, and Schröder (2008) which is derived by a different method.

It is worth noting that these results do not depend on the way we compute $q_{t}$ and $\bar{q}_{t}$. We also consider the fundamental value to simply be represented by the moving average of the exchange rate over the previous ten years, and impose that exchange rates are assumed to mean-revert when they have deviated from this value. The results we find when measuring the deviation by $\left|s_{t}-\bar{s}_{t}\right|$ or $\left|s_{t}-\bar{s}_{t}\right|^{2}$ respectively, are very similar.

Overall, this picture is in line with the notion of non-linearity of the relationship between exchange rates and fundamentals, and confirms our Hypothesis 5, albeit with the restriction that only pronounced misalignments will have a (negative) impact on the adoption of chartist rules.

Dynamics under high or low fundamental misalignment. To look more into the details of the non-linear influence of fundamental misalignment on the forecasting dynamics, we reconsider our Hypotheses 4 and 5 and analyze the influence of $\Delta r_{t}^{\text {expost(30) }}$ and $\Delta\left|q_{t}-\bar{q}_{t}\right|$ on forecasting behavior under different conditions. More specifically, we distinguish states with high and low deviations of the exchange rate from its fundamental value. We find the effects of our Hypothesis 4 (switch to trend-following after good performance in the recent past) to be particularly pronounced when fundamental misalignment is low, whereas the effects of our Hypothesis 5 (fundamental misalignment reduces trend-following) are only valid when fundamental misalignment is large.

For this analysis, we classify all periods in which $\left|q_{t}-\bar{q}_{t}\right|$ is smaller than its median $X_{50}\left(\left|q_{t}-\bar{q}_{t}\right|\right)$ as low deviations states, and the periods with $\left|q_{t}-\bar{q}_{t}\right|>X_{50}\left(\left|q_{t}-\bar{q}_{t}\right|\right)$ as high deviations states. We estimate the dynamic relationship in Eq. (7) for both states separately, i.e.,

$$
\Delta \mathrm{SHARE}_{t}^{30}= \begin{cases}a_{01}+a_{11} \Delta \mathrm{SHARE}_{t-1}^{30}+a_{21} \Delta X_{t}+e_{t} & \text { if }\left|q_{t}-\bar{q}_{t}\right|<X_{50}\left(\left|q_{t}-\bar{q}_{t}\right|\right) \\ a_{02}+a_{12} \Delta \mathrm{SHARE}_{t-1}^{30}+a_{22} \Delta X_{t}+e_{t} & \text { if }\left|q_{t}-\bar{q}_{t}\right|>X_{50}\left(\left|q_{t}-\bar{q}_{t}\right|\right)\end{cases}
$$


As covariates, we consider the change in the absolute return of a momentum strategy over the last 30 days, $\Delta r_{t}^{\text {expost(30) }}$, as well as the change in the deviation from PPP, $\Delta\left|q_{t}-\bar{q}_{t}\right|$. Table 9, Panel A, displays the results.

[Table 9 about here]

Table 9, (i) and (iv), show that the coefficient for $\Delta r_{t}^{\text {expost(30) }}$ is not significantly different from zero at any conventional significant levels in the high deviation states, whereas it is strongly significant at the $1 \%$ level in the low deviation states. The economic significance of the estimates points into the same direction: as can be derived from Panel B, an increase of $\Delta r_{t}^{\text {expost(30) }}$ by one standard deviation in the low (high) deviation states leads to an increase of $\Delta \mathrm{SHARE}_{t}^{30}$ by more than one third (less than one forth) standard deviation. Thus, the effects of our Hypothesis 4 matter more when fundamental misalignment is small.

Unexpectedly, Table 9, specification (ii), demonstrates that $\Delta\left|q_{t}-\bar{q}_{t}\right|$ carries even a positive sign for the low deviation states, although without contributing too much to explanatory power. Reassuringly, specification (iv) shows a negative sign of $\Delta\left|q_{t}-\bar{q}_{t}\right|$ for the high deviation states. For the latter, the $R^{2}$ of the corresponding specification is much large than for the former. This sign-switching pattern explains why $\Delta\left|q_{t}-\bar{q}_{t}\right|$ does not enter significantly in our analysis in the previous paragraph (see Table 8), and why only $\Delta\left|q_{t}-\bar{q}_{t}\right|^{2}$ reveal the effects as postulated by our Hypothesis 5. Thus, changes in fundamental misalignment only determine the forecasters' behavior when the level of fundamental misalignment is already large - a notion which corresponds to the non-linear relationship in many models.

Switching of chartists and fundamentalists. In this paragraph, we only consider those forecasters who have been classified as fundamentalists and chartists, respectively, and compute $\Delta \mathrm{SHARE}_{t}^{30}$ for these two groups separately. We then conduct the regressions introduced by Eq. (7). Table 10 present the results for chartists and fundamentalists, respectively. 
[Table 10 about here]

Overall, the time series analysis based on these two groups reconfirms the findings made above: both groups tend to adopt chartist forecasting roles when the observed trends have increased in the previous months, and tend to abandon these rules when fundamental misalignments are pronounced. The negative coefficient for the $\mathrm{AR}(1)$ term is more pronounced for chartists than for fundamentalists, which reconfirms that chartists switch their strategies more frequently than fundamentalists. This observation is also in line with the chartists' self-assessment that they additionally rely on alternative approaches. Moreover, the negative coefficient of the squared distance from the PPP value is more pronounced for fundamentalists, indicating that this group is particularly sensitive to severe misalignments of the exchange rate to its fundamental value. This finding is also in line with intuition.

\subsection{Results on forecasting performance}

As discussed above, the profitability of chartists' and fundamentalists' predictions is controversial. We investigate whether both chartist and fundamentalist investors can survive in the market, i.e. whether none of our groups is superior in terms of forecasting performance (our Hypothesis 6). We illustrate that this holds generally true, albeit chartists appear to be rather superior as far as very short horizons are concerned.

In order to assess the performance of forecasters we use two measures. First, we compute the average return of a trading strategy for each individual forecaster's FX predictions. Second, we take the same data as input but use a risk-adjustment, here the Sharpe ratio. Both ideas imply that the forecaster targets an investment into a currency on a fixed horizon (either holding a long or a short position), and we thus measure trading performance with these measures. ${ }^{3}$

For both measures, we follow the concept introduced in Dick, MacDonald, and Menkhoff (2011)

\footnotetext{
${ }^{3}$ In the later robustness Section 5, we also compute absolute average forecast errors for each forecaster.
} 
and translate the individual forecasts into trading strategies, going long USD (in the forward market) when they expect the USD to appreciate, and short when they expect the opposite. Each position will be closed in the spot market at the end of the investment period of $k$ months. As the forecasters are asked to provide a six-month-ahead forecast, it is natural to focus on investments with a six-months-horizon $(k=6)$, but we will in addition also consider different investment horizons, i.e. one-, two-, three-, twelve-, 24, and 36-month horizons. Formally, the trading rule is given by

$$
r_{t, t+k}^{T R_{I N D, k}}=I_{t}\left(s_{t}>E_{t}^{(I N D)}\left[s_{t+k}\right]\right)\left(f_{t, k}-s_{t+k}\right)+I_{t}\left(s_{t}<E_{t}^{(I N D)}\left[s_{t+k}\right]\right)\left(s_{t+k}-f_{t, k}\right)
$$

where $s_{t}$ denotes the log exchange rate of one Euro expressed in USD in month $t, f_{t, k}$ denotes the $\log$ $k$-month forward rate in month $t$ and $E_{t}^{(I N D)}$ represents an individual expectation of forecaster $i$. For each forecaster, we compute the average monthly return of such trading strategies over time as well as the annualized Sharpe ratios. Table 11 shows the averages for the groups of fundamentalists and chartists, respectively.

[Table 11 about here]

Taking first a look at investments with a six-month horizon, it becomes apparent that chartists and fundamentalists are not systematically different in terms of their forecasting performance: chartists are slightly superior in terms of average returns (Panel A), whereas fundamentalists exhibit slightly larger Sharpe ratios (Panel B), but these findings are far from being significantly different. Note that the annualized average Sharpe ratio is not impressive for any of these two groups, and given the fact that we have not taken transaction costs into account, our results do not indicate that it is profitable to trade according to the average chartist's or average fundamentalist's implicit trading rule.

This latter result does not change when we take investment horizons into consideration which are different from six months. However, we do observe gradual changes in the relative average 
performance of chartists and fundamentalists: in fact, Table 11 suggests that chartists' forecasts lead to more profitable trading strategies than fundamentalists' forecasts when their forecasts are translated into investments on the one-month-horizon. The average monthly returns are 0.21 percent on average for chartists, and only 0.06 percent for fundamentalists; the Sharpe ratios amount to 0.25 for chartists compared to 0.06 for fundamentalists. The significance of the difference is more pronounced for average returns than for Sharpe ratios, but chartists are also superior according to the latter criterion at least at the ten-percent significance level. On a two-month horizon, the average returns based on FX predictions of chartists are also significantly superior to those based on predictions made by fundamentalists; however, the corresponding difference is not significant any more as far as Sharpe ratios are concerned. For investments at horizons longer than two months, we do not find significant differences between the forecasting performance of chartists and fundamentalists.

Overall, it is apparent that chartists perform significantly better than fundamentalists at very short horizon trading strategies. In contrast, the forecasts made by fundamentalists are somewhat better suited to make predictions at intermediate- and long-term horizons than short term horizons, which can be seen in the increasing Sharpe ratios for this group. Our findings corroborate the idea that fundamentalists and chartists forecast on different horizons (e.g. Taylor and Allen, 1992), and it is thus perceivable that fundamentalists might be rather long-term oriented investors and their forecasts may not be meant to be evaluated at short-term horizons such as one month. For longer horizons, in contrast, fundamentalists and chartists appear to be comparably profitable, which supports Hypothesis 6 and underlines the efficiency of FX markets in this important respect.

\section{Robustness}

This section informs about several robustness tests we have performed; they do not qualitatively affect our findings. (i) We test whether our result on the importance of trends and deviation from 
PPP for expectation formation is robust to the possibility that forecasters follow a PPP strategy or a carry trade strategy. Furthermore, we test whether the results hold when (ii) controlling for volatility and (iii) without including the autoregressive term in Eq. (7). (iv) Finally, we test the robustness of our approach by substituting the trading strategy as a measure of performance by a measure of forecast accuracy.

Controlling for alternative trading rules. So far and throughout this study, our LHS variable in Eq. (7) corresponds to the change in the share of forecasters which are in line with a forecast based on a momentum-following forecasting rule. However, it has to be noted that a forecast, while being in line with a particular rule, is nevertheless not with certainty based on that particular rule. In this paragraph we address the possibility that forecasters have made their forecasts on a different, i.e. PPP-oriented trading rule or carry trade rule.

To ensure that our results in the main part are not driven by the coincidence between the predictions from alternative rules, we consider both a forecasting rule based on fundamental analysis, i.e. a rule presented expecting mean-reversion to PPP, and a carry-trade-based forecasting rule. ${ }^{4}$ We compute the proportion of forecasters whose forecasts are in line with those strategies, i.e. $\mathrm{SHARE}_{t}^{P P P}$ and $\mathrm{SHARE}_{t}^{C T}$. We then include $\triangle \mathrm{SHARE}_{t}^{P P P}$ and $\triangle \mathrm{SHARE}_{t}^{C T}$ as control variables into the regression in Eq. (7).

Table 8, (vi), displays the results of this specification, and reveals that, in fact, the coefficient for $\triangle \mathrm{SHARE}_{t}^{P P P}$ is positive and significant at the five-percent level. Thus, in our sample, there appears to be a slight tendency for momentum rules and fundamental rules to point into the same direction. Importantly, however, the inclusion of these control variables does not alter any of the other coefficients in a substantial way. Overall, the main results for our Hypotheses 4 and 5 are also confirmed in this setting.

\footnotetext{
${ }^{4}$ The PPP rule follows the concept from Eq. (4), whereas the carry trade rule is given by$$
E\left[\Delta s_{t, t+k}\right]=\phi^{(k, C T)}\left(i_{t}^{E U R}-i_{t}^{U S}\right) \text { with } \phi^{(k, C T)}>0
$$

with $i_{t}^{E U R}$ and $i_{t}^{U S}$ representing the 3-month-interbank rates in the Eurozone and the United States, respectively.
} 
Controlling for volatility. We also test whether our results in Section 4.2 hold when we control for volatility. A positive association between turbulence in markets and the use of chartist rules has been postulated by, e.g., De Grauwe and Grimaldi (2006). More specifically, we compute the standard deviation of daily returns during the 30 days before an individual forecast has been made, and take the cross-sectional mean of these values for each survey period $t$, henceforth $\sigma_{t}^{(30)}$. A survey period characterized by high average volatility measures is interpreted to be particularly turbulent, and we consider changes in volatility $\Delta \sigma_{t}^{(30)}$ as a variable of interest in our regression Eq. (7).

As Table 8 , (vii), shows, the coefficient for $\Delta \sigma_{t}^{(30)}$ is not significantly different from zero; in addition, the results from the main part remain virtually unchanged. This result also holds when we compute volatility over different horizons (10 days or 90 days), or when we include the variance instead of the standard deviation as a measure of volatility (unreported).

Ignoring the autoregressive term. So far, we have studied the dynamics of joining or abandoning trend-following forecasting by considering Eq. (7), which captures a lagged dependent variable. As a robustness check, we also reconsider the dynamics with a specification without an $\operatorname{AR}(1)$ term, i.e.,

$$
\Delta \operatorname{SHARE}_{t}^{30}=a_{0}+a_{2} \Delta X_{t}+e_{t}
$$

Table 12 presents the results and reconfirms that increases in trend size lead to an increased fraction of professionals with forecasts in line with momentum strategies. It also underlines that this fraction decreases when the squared distance from the fundamental value increases. Our conclusions from the main part with respect to Hypotheses 4 and 5 do thus not depend on the inclusion of a lagged dependent variable into the time series regressions.

[Table 12 about here] 
Forecast errors. To illustrate that the results of our discussion of Hypothesis 6 are not driven by the way how we formulate trading strategies, we also apply an entirely different concept and compute the individual forecasters' average absolute forecast errors.

To do so, the directional forecasts (e.g., the USD appreciates, stagnates, depreciates) are coded for simplicity in $X_{i, t+k}^{e}=\{-1,0,1\}$. Likewise, the realizations (ex post changes of exchange rates) are also categorized into three corresponding groups. For the neutral (no-change) category, we choose symmetric threshold values such that, over the entire time span, the share of observations in the no-change category for realizations is as large as the share of forecasts in this category. Thus, the thresholds differ according to the forecasting horizon. ${ }^{5}$ It has to be noted that forecasters can be mistaken to two different extents: they make a small error when they predict an unchanged variable, whereas the actual outcome is an increase, but a large error if they predict a decline. We take this into account by computing absolute forecast errors by $|\epsilon|_{i, t+k}^{e}=\left|X_{i, t, t+k}^{e}-X_{t, t+k}\right|$, which takes on the value of 2 for a severe error, 1 for a small error and 0 for a correct prediction. Table 13 presents the average absolute forecast errors for the groups of chartists and fundamentalists.

[Table 13 about here]

Table 13 shows very similar results as our findings in the main part, which confirms that our support for Hypothesis 6 is not driven by the choice of the trading strategy discussed above: chartists commit less (and less severe) forecast errors on one-month horizons. In contrast, there are no significant differences between chartists and fundamentalists when the forecasts are interpreted with respect to their predictability on longer horizons.

\footnotetext{
${ }^{5}$ The neutral category is chosen for one-month changes within the range of -1.19 percent and +1.19 percent, twomonth changes between $+/-1.7$ percent, three-month changes between $+/-2$ percent, six-month changes between $+/-4$ percent, twelve-month changes between $+/-6.455$ percent, 24 -month-changes between $+/-5.7$ percent, and 36-month-changes between $+/-8.85$ percent.
} 


\section{Conclusions}

The formation of exchange rates, and thus the formation of respective expectations, is a complex phenomenon as the limited understanding of this process indicates. One root of complexity is the existence of quite heterogeneous agents, in particular their reliance on either "charts" or "fundamentals" when forming expectations. There is ample evidence showing that these two forms of analysis are indeed of great importance for practitioners (Menkhoff and Taylor, 2007). This has been a motivation to construct models of heterogeneous agents in foreign exchange markets relying on these two forms of analysis. The resulting interplay of chartists and fundamentalists provides useful stylized facts. However, models of this kind rely on plausible but rather untested assumptions about the behavior of heterogeneous agents in foreign exchange. This study provides novel evidence about the role of chartists and fundamentalists in the process of exchange rate formation.

We provide clear support for the core assumptions of chartist-fundamentalist models, such as formulated by De Grauwe and Grimaldi (2006), Bauer, De Grauwe, and Reitz (2009) or Dieci and Westerhoff (2010). In particular, we find that (1) chartists and fundamentalists do indeed form different exchange rate expectations; chartists' expectations are more in line with trends while fundamentalists consider mean reversion slightly more. (2) Chartists change their forecast direction more often than fundamentalists and in this sense contribute to instability. However, despite the differences between chartists and fundamentalists, there are strong common changes in expectations, in particular when exchange rates deviate strongly from long-run averages. (3) Chartists' exchange rate expectations are as good as fundamentalists' or the market average, and they are even better at short horizons, so that chartists can survive in the market. This does not support the conventional understanding of efficient financial markets, as described in Fama (1991).

All these findings are derived from a new perspective clearly supporting the appropriateness of the chartist-fundamentalist model in foreign exchange. This research is the first - to the best of our knowledge - to systematically link data about expectation formation with self-stated preferences 
for charts or fundamentals. We thus provide more direct evidence on chartist-fundamentalist approaches than earlier studies, which rely on either only parts of this information (exchange rate expectations or the use of analytical tools), or on simulations of artificial markets or on experiments.

Nevertheless, some caveats remain: Regarding our research, the evidence is based on forecasters who are not themselves investors, so that answers may be biased, e.g., favoring longer horizons than foreign exchange traders. Regarding the chartist-fundamentalist models, these are highly stylized and reduce market behavior in drastic ways: e.g., chartist behavior is more than trendfollowing and fundamental behavior reaches beyond PPP-orientation. This may be considered more explicitly in future research. 


\section{References}

Barberis, N., A. Shleifer, and R. Vishny (1998): "A Model of Investor Sentiment," Journal of Financial Economics, 49(3), 307-343.

Bauer, C., P. De Grauwe, and S. Reitz (2009): "Exchange Rate Dynamics in Target Zones - A Heterogeneous Expectations Framework," Journal of Economic Dynamics and Control, 33, 329-344.

Beine, M., P. De Grauwe, and M. Grimaldi (2009): "The Impact of FX Central Bank Intervention in a Noise Trading Framework," Journal of Banking and Finance, 33(7), 11871195.

Bloomfield, R., W. Tayler, and F. Zhou (2009): "Momentum, Reversal, and Uninformed Traders in Laboratory Markets," Journal of Finance, 64(6), 2535-2558.

Brock, W., and C. Hommes (1997): "A Rational Route to Randomness," Econometrica, 65(5), 1059-1095.

(1998): "Heterogeneous Beliefs and Routes to Chaos in a Simple Asset Pricing Model," Journal of Economic Dynamics and Control, 22(8-9), 1235-1274.

Burnside, C. (2011): "Carry Trade and Risk," NBER WP 17278.

Cheung, Y., M. Chinn, and A. Garcia-Pascual (2005): "Empirical Exchange Rate Models of the Nineties: Are Any Fit to Survive?," Journal of International Money and Finance, 24(7), $1150-1175$.

Cheung, Y.-W., And M. D. Chinn (2001): "Currency Traders and Exchange Rate Dynamics: A Survey of the US Market," Journal of International Money and Finance, 20, 439-471.

Cheung, Y. W., M. D. Chinn, and I. Marsh (2004): "How Do UK-based Foreign Exchange Dealers Think their Market Operates?," International Journal of Finance and Economics, 9, 289-306.

Chiarella, C., R. Dieci, and L. Gardini (2002): "Speculative Behaviour and Complex Asset Price Dynamics: a Global Analysis," Journal of Economic Behavior and Organization, 49(2), 173-197.

Day, R., And W. Huang (1990): "Bulls, Bears and Market Sheep," Journal of Economic Behavior and Organization, 14(3), 299-329.

De Grauwe, P., and M. Grimaldi (2006): "Exchange Rate Puzzles: A Tale of Switching Attractors," European Economic Review, 50(1), 1-33.

Delong, J., A. Shleifer, L. Summers, and R. Waldmann (1989): "Positive Feedback Investment Strategies and Destabilizing Rational Speculation," Journal of Finance, 45(2), 379-395.

Dick, C. D., R. MacDonald, and L. Menkhoff (2011): "Individual Exchange Rate Forecasts and Expected Fundamentals," ZEW Discussion Paper 11-062.

Dieci, R., And F. Westerhoff (2010): "Heterogeneous Speculators, Endogenous Fluctuations and Interacting Markets: a Model of Stock Prices and Exchange Rates," Journal of Economic Dynamics and Control, 34(4), 743-764.

Dumas, B. (1993): "Dynamic Equilibrium and the Real Exchange Rate in a Spatially Separated World," Review of Financial Studies, 5(2), 153-180.

FAmA, E. F. (1991): "Efficient Capital Markets II," Journal of Finance, 46(5), 1575-1643.

FAmA, E. F. (1998): "Market Efficiency, Long-Term Returns and Behavioral Finance," Journal of Financial Economics, 49(3), 283-306. 
Farmer, J., and S. Joshi (2002): "The Price Dynamics of Common Trading Strategies," Journal of Economic Behavior and Organization, 49(2), 149-171.

Föllmer, H., U. Horst, and A. Kirman (2005): "Equilibria in Financial Markets with Heterogeneous Agents: a Probabilistic Perspective," Journal of Mathematical Economics, 41(1), $123-155$.

Frankel, J. A., and K. A. Froot (1987): "Using Survey Data to Test Standard Propositions Regarding Exchange Rate Expectations," American Economic Review, 77(1), 133-153.

_ (1990): "Chartists, Fundamentalists, and Trading in the Foreign Exchange Market," American Economic Review, 80(2), 181-185.

Goodman, S. (1979): "Foreign Exchange Rate Forecasting Techniques: Implications for Business and Policy," Journal of Finance, 34(2), 415-427.

Haruvy, E., Y. Lahav, and C. Noussair (2007): "Traders' Expectations in Asset Markets: Experimental Evidence," American Economic Review, 97(5), 1901-1920.

Hommes, C. (2011): "The Heterogeneous Expectations Hypothesis: Some Evidence From the Lab," Journal of Economic Dynamics and Control, 35(1), 1-24.

Iто, T. (1990): "Foreign Exchange Rate Expectations: Micro Survey Data," American Economic Review, 80(3), 434-449.

Jongen, R., W. F. C. Verschoor, and C. C. P. Wolff (2008): "Foreign Exchange Rate Expectations: Survey and Synthesis," Journal of Economic Surveys, 22(1), 140-165.

Jongen, R., W. F. C. Verschoor, C. C. P. Wolff, and R. C. J. Zwinkels (2012): "Explaining Dispersion in Foreign Exchange Expectations: A Heterogeneous Agent Approach," Journal of Economic Dynamics and Control, forthcoming.

Kilian, L., and M. Taylor (2003): "Why Is It so Difficult to Beat the Random Walk Forecast of Exchange Rates?," Journal of International Economics, 60(1), 85-107.

Lux, T. (1998): "The Socio-Economic Dynamics of Speculative Markets: Interacting Agents, Chaos, and the Fat Tails of Return Distributions," Journal of Economic Behavior and Organization, 33(2), 143-165.

MacDonald, R. (2000): "Expectations Formation and Risk in Three Financial Markets: Surveying what the Surveys Say," Journal of Economic Surveys, 14(1), 69-100.

MacDonald, R., and I. W. Marsh (1996): "Currency Forecasters are Heterogeneous: Confirmation and Consequences," Journal of International Money and Finance, 15(1), 665-685.

Manzan, S., and F. Westerhoff (2007): "Heterogeneous Expectations, Exchange Rate Dynamics and Predictability," Journal of Economic Behavior and Organization, 64(1), 111-128.

Meese, R., and K. Rogoff (1983): "Empirical Exchange Rate Models of the Seventies: Do they Fit out of Sample?," Journal of International Economics, 14(1-2), 3-24.

Menkhoff, L., R. Rebitzky, and M. Schröder (2008): "Do Dollar Forecasters Believe too Much in PPP?," Applied Economics, 40 (3), 261-270.

Menkhoff, L., R. R. Rebitzky, and M. Schröder (2009): "Heterogeneity in Exchange Rate Expectations: Evidence on the Chartist-Fundamentalist Approach," Journal of Economic Behavior and Organization, 70, 241-252.

Menkhoff, L., L. Sarno, M. Schmeling, and A. Schrimpf (2012): "Currency Momentum Strategies," Journal of Financial Economics, forthcoming.

Menkhoff, L., and M. P. Taylor (2007): "The Obstinate Passion of Foreign Exchange Professionals: Technical Analysis," Journal of Economic Literature, 45, 936-972. 
Neely, C., And P. Weller (2011): "Technical Analysis in the Foreign Exchange Market," Wiley Handbook of Exchange Rates, forthcoming.

Neely, C., P. Weller, And J. Ulrich (2010): "The Adaptive Markets Hypothesis: Evidence from the Foreign Exchange Market," Journal of Financial and Quantitative Analysis, 44(2), 467.

Obstfeld, M., And K. Rogoff (2000): "The Six Major Puzzles in International Macroeconomics: Is There a Common Cause?," NBER Macroeconomics Annual 2000, 15, 339-390.

Okunev, J., And D. White (2003): "Do Momentum-Based Strategies Still Work in Foreign Currency Markets?," Journal of Financial and Quantitative Analysis, 38(2), 425-447.

Park, C., And S. Irwin (2007): "What Do We Know About the Profitability of Technical Analysis," Journal of Economic Surveys, 21, 786-826.

Pukthuanthong, K., R. Levich, and L. Thomas III (2007): "Do Foreign Exchange Markets Still Trend?," Journal of Portfolio Management, 34, 114-118.

QI, M., ANd Y. Wu (2006): "Technical Trading-Rule Profitability, Data Snooping, and Reality Check: Evidence from the Foreign Exchange Market," Journal of Money, Credit and Banking, $38,2135-2158$.

Reitz, S., J. Rülke, and G. Stadtmann (2012): "Nonlinear Expectations in Speculative Markets-Evidence from the ECB Survey of Professional Forecasters," Journal of Economic Dynamics and Control, forthcoming.

Röтheli, T. (2011): "Pattern-Based Expectations: International Experimental Evidence and Markets- Evidence from the ECB Survey of Professional Forecasters," Review of Economics and Statistics, 93, 1319-1330.

Schmeling, M., And A. Schrimpf (2011): "Expected Inflation, Expected Stock Returns, and Money Illusion: What Can we Learn From Survey Expectations," European Economic Review, 55(5), 702-719.

Sonnemans, J., C. Hommes, J. Tuinstra, and H. Van De Velden (2004): "The Instability of a Heterogeneous Cobweb Economy: a Strategy Experiment on Expectation Formation," Journal of Economic Behavior and Organization, 54(4), 453-481.

Taylor, M., and H. Allen (1992): "The Use of Technical Analysis in the Foreign Exchange Market," Journal of International Money and Finance, 11(3), 304-314.

Taylor, M., D. Peel, and L. Sarno (2001): "Nonlinear Mean-Reversion in Real Exchange Rates: Toward a Solution to the Purchasing Power Parity Puzzles," International Economic Review, 42(4), 1015-1042.

Tramontana, F., F. Westerhoff, and L. Gardini (2010): "On the Complicated Price Dynamics of a Simple One-Dimensional Discontinuous Financial Market Model with Heterogeneous Interacting Traders," Journal of Economic Behavior and Organization, 74(3), 187-205.

Westerhoff, F. (2004): "Multiasset Market Dynamics," Macroeconomic Dynamics, 8(5), 596616. 
Table 1: Weighting of forecasting tools

This table reports the self-assessment of professional forecasters with respect to their preferred forecasting tools. In special surveys in 2004/01, 2007/04, and 2011/09 the forecasters are asked to attach weights to technical analysis (Tech.), fundamentalist analysis (Fund.) and the analysis of order flow (OF), depending on their usage of these techniques for their FX predictions. This table reports the cross-sectional mean as well as the standard deviation of these figures.

\begin{tabular}{l|rrr|rrr|rrr}
\hline \hline & \multicolumn{3}{|c|}{ Jan 2004 } & \multicolumn{3}{|c|}{ April 2007 } & \multicolumn{3}{c}{ Sept. 2011 } \\
& Fund. & Tech. & OF & Fund. & Tech. & OF & Fund. & Tech. & OF \\
\hline Mean & 60.0 & 29.9 & 10.1 & 57.6 & 28.6 & 13.8 & 57.4 & 27.4 & 15.2 \\
SD & 21.6 & 19.8 & 11.9 & 20.3 & 17.1 & 12.7 & 22.0 & 18.0 & 14.1 \\
$\mathrm{~N}$ & 237 & 237 & 237 & 247 & 247 & 247 & 198 & 198 & 198 \\
\hline \hline
\end{tabular}

Table 2: Groups

This table reports characteristics of the defined groups of fundamentalists, chartists, and intermediates. Based on the self-assessed usage of forecasting tools in the special surveys, we classify forecasters as chartists when they put a stronger weight on chartist than on fundamental information, unless the weight on chartist information is below 40 percent. To keep groups similarly large, we define forecasters to be fundamentalists when they attach a weight of at least 80 percent to fundamental analysis. The table displays the mean, standard deviation, minimum and maximum weight (in percent) for fundamental and technical analysis, respectively, for all groups separately.

\begin{tabular}{l|c|rrrr|rrrr}
\hline \hline & & \multicolumn{4}{|c|}{ Fundamental analysis } & \multicolumn{4}{|c}{ Technical analysis } \\
& $\mathrm{N}$ & Mean & SD & Min & Max & Mean & SD & Min & Max \\
\hline fundamentalists & 65 & 88.8 & 8.4 & 80.0 & 100.0 & 7.2 & 7.7 & 0.0 & 20.0 \\
intermediates & 271 & 58.3 & 12.1 & 20.0 & 78.3 & 27.3 & 10.3 & 0.0 & 50.0 \\
chartists & 60 & 30.4 & 10.3 & 0.0 & 45.0 & 55.8 & 11.7 & 40.0 & 92.5 \\
\hline \hline
\end{tabular}


Table 3: Changes of preferences over time

These tables illustrate how preferences with respect to forecasting tools (fundamental or technical analysis) change over time. We use the identical classification rules described in Table 2 for each of the three special surveys separately and consider those forecasters who have responded to at least two of these. The contingency tables show the transition of forecasters w.r.t. these groups from one special survey to another one (Panel A: from April 2007 to Sept. 2011; Panel B: from Jan. 2004 to Sept. 2011). The figures in the tables refer to the number of forecasters. The Pearson $X^{2}$ tests against the $H_{0}$ that the classification of a forecaster based on one special survey is independent from the classification in the other special survey. (***: $1 \%, * *: 5 \%, *: 10 \%$ significance level).

\begin{tabular}{|c|c|c|c|c|c|}
\hline \multicolumn{2}{|c|}{ Panel A } & \multicolumn{4}{|c|}{ Apr. 2007} \\
\hline & & fundamentalists & intermediates & chartists & $\Sigma$ \\
\hline \multirow{4}{*}{ Sept. 2011} & fundamentalists & 14 & 15 & 1 & 30 \\
\hline & intermediates & 8 & 68 & 6 & 82 \\
\hline & chartists & 0 & 14 & 9 & 23 \\
\hline & $\Sigma$ & 22 & 97 & 16 & 135 \\
\hline \multicolumn{6}{|c|}{ Pearson $X_{4}^{2} \quad * * * 44.36$} \\
\hline \multirow{2}{*}{\multicolumn{2}{|c|}{ Panel B }} & \multicolumn{4}{|c|}{ Jan. 2004} \\
\hline & & fundamentalists & intermediates & chartists & $\Sigma$ \\
\hline \multirow{4}{*}{ Sept. 2011} & fundamentalists & 12 & 8 & 1 & 21 \\
\hline & intermediates & 11 & 39 & 8 & 58 \\
\hline & chartists & 2 & 5 & 7 & 14 \\
\hline & $\Sigma$ & 25 & 52 & 16 & 93 \\
\hline Pearson $X_{4}^{2}$ & $* * * 23.92$ & & & & \\
\hline
\end{tabular}

Table 4: Comparing panelists with all forecasters

This table compares the forecasts issued by the analysts considered in this study (panelists: the 396 forecasters who have also responded to special questions about their preferred forecasting tools) with all 744 forecasters in the dataset (all forecasters). (Both groups only include the forecasters with at least 10 survey responses.) For each point in time, we compute the proportion of forecasters (for both groups separately) who predict an appreciation, no-change, and a depreciation of the USD against the Euro. The means and standard deviations (over time) of these proportions are compared in this table. The table also reports the mean of the absolute difference as well as the Pearson correlation coefficient of the time series of proportions for both panelists and all forecasters.

\begin{tabular}{l|r|lr|rr|rr}
\hline \hline & & \multicolumn{2}{|c|}{ Apprec. of USD } & \multicolumn{2}{|c|}{ No-change } & \multicolumn{2}{|c}{ Deprec. of USD } \\
& $\mathrm{N}$ & Mean & Std. & Mean & Std. & Mean & Std. \\
\hline Panelists & 396 & 0.219 & 0.116 & 0.290 & 0.059 & 0.490 & 0.137 \\
All forecasters & 744 & 0.220 & 0.116 & 0.295 & 0.062 & 0.485 & 0.138 \\
\hline Mean of absolute differences & & 0.011 & & 0.013 & & 0.014 & \\
Correlation & & 0.993 & & 0.958 & & 0.991 & \\
\hline \hline
\end{tabular}


Table 5: Self-assessment and revealed behavior, correlations

This table reports Pearson correlation coefficients. Panel A shows the correlation of the individual percentage share of forecasts made in line with the momentum strategy $\operatorname{SHARE}_{i}^{D D}$ (where $D D$ denotes the days of the considered trend, i.e. 10, 30, 60, 90, and 180 days) with the individual survey response about the weights (in percent) attributed to fundamental and technical analysis, respectively. Panel B shows the correlation of the individual percentage share of forecasts made in line with the PPP with the individual survey response about the weights (in percent) attributed to fundamental and technical analysis, respectively. (***: $1 \%,{ }^{* *}: 5 \%, *: 10 \%$ significance level).

\begin{tabular}{l|rrrrr|r}
\hline \hline & \multicolumn{5}{|c|}{ Panel A } & Panel B \\
\hline & SHARE $_{i}^{10}$ & SHARE $_{i}^{30}$ & SHARE $_{i}^{60}$ & SHARE $_{i}^{90}$ & SHARE $_{i}^{180}$ & SHARE $_{i}^{P P P}$ \\
\hline fund. analysis (in \%) & $* * *-0.14$ & $* * *-0.16$ & $* * *-0.14$ & -0.08 & -0.07 & -0.08 \\
techn. analysis (in \%) & $*_{0.11}$ & $* * 0.12$ & $*_{0} 0.09$ & 0.03 & 0.01 & 0.08 \\
\hline \hline
\end{tabular}

Table 6: Revealed behavior for different groups, averages

Panel A reports the average individual percentage share of forecasts made in line with the momentum strategy $\mathrm{SHARE}^{D D}$ (where $D D$ denotes the days of the considered trend, i.e. 10, 30, 60, 90, and 180 days) for the groups of chartists, fundamentalists and intermediates. Panel B reports the average individual percentage share of forecasts made in line with PPP. The last row displays the results of t-statistic, where the $H_{0}$ corresponds to equal means between chartists and fundamentalists. (***: $1 \%, * *: 5 \%, *: 10 \%$ significance level).

\begin{tabular}{l|rrrrr|r}
\hline \hline & \multicolumn{5}{|c|}{ Panel A } & Panel B \\
\hline & SHARE $^{10}$ & SHARE $^{30}$ & SHARE $^{60}$ & SHARE $^{90}$ & SHARE $^{180}$ & SHARE $^{P P P}$ \\
\hline fundamentalists & 0.34 & 0.34 & 0.35 & 0.37 & 0.37 & 0.33 \\
intermediates & 0.38 & 0.38 & 0.39 & 0.39 & 0.39 & 0.35 \\
chartists & 0.39 & 0.39 & 0.40 & 0.40 & 0.41 & 0.33 \\
\hline t-test fund. vs. chart. & $* * 2.26$ & $* * 2.54$ & $* * 2.26$ & 1.16 & 1.02 & 0.08 \\
\hline \hline
\end{tabular}


Table 7: Switching probability, correlations and mean

Panel A reports Pearson correlation coefficients for the correlation of the individual probability of switching the direction of an USD/EUR forecast from one month to the next with with the individual survey response about the weights (in percent) attributed to fundamental and technical analysis, respectively. Panel B reports the average individual probability of switching the direction of an USD/EUR forecast from one month to the next for the groups of chartists, fundamentalists and intermediates. The last row displays the results of t-statistic, where the $H_{0}$ corresponds to equal means between chartists and fundamentalists. (***: 1\%, **: 5\%, *: $10 \%$ significance level).

\begin{tabular}{l|r}
\hline \hline Panel A & Correlation with switching probability \\
\hline $\begin{array}{l}\text { fundamental analysis (in \%) } \\
\text { technical analysis (in \%) }\end{array}$ & ${ }^{* * *} 0.16$ \\
$* * * 0.16$ \\
\hline \hline Panel B & Mean switching probability, by group \\
\hline fundamentalists & 0.09 \\
intermediates & 0.11 \\
chartists & 0.14 \\
\hline t-test fund. vs. chartists & $2.35^{* *}$ \\
\hline \hline
\end{tabular}


Table 8: Explaining switching into momentum strategies, time series regressions

This table reports the results of a regression of the type

$$
\Delta \operatorname{SHARE}_{t}^{30}=a_{0}+a_{1} \Delta \mathrm{SHARE}_{t-1}^{30}+a_{2} \Delta X_{t}+e_{t}
$$

where $\triangle \mathrm{SHARE}_{t}^{30}$ denotes the change in the proportion of forecasts made in $t$ which point into the same direction as a trading rule following the trend over the previous 30 days, $\Delta \mathrm{SHARE}_{t-1}^{30}$ a lagged dependent variable and $\Delta X_{t}$ represents the changes in several control variables. These control variables include the ex-post return of a strategy which has followed the trend of the previous 30 days, $r_{t}^{\text {expost (30) }}$, the previous month's return of a momentum-strategy chosen on the basis of the trend the month before, $r_{t}^{T R(30)}$, the deviation of the real exchange rate from its moving average of the preceding 10 years, $\left|q_{t}-\bar{q}_{t}\right|$, and the square of this distance, $\left(q_{t}-\bar{q}_{t}\right)^{2}$. In addition, we include $\triangle \mathrm{SHARE}_{t}^{P P P}$ and $\triangle \mathrm{SHARE}_{t}^{C T}$, which denote the change in the proportion of forecasts made in $t$ which point into the same direction as a PPP-oriented (carry-trade oriented) forecast as further control variables. Due to potential time overlaps (the forecasts are made on a six-month horizon, whereas we sample at monthly frequency), we use Newey-West standard errors with a lag length of five months. Standard errors are provided in parentheses. (***: $1 \%, * *: 5 \%, *: 10 \%$ significance level).

\begin{tabular}{|c|c|c|c|c|c|c|c|}
\hline & (i) & (ii) & (iii) & (iv) & (v) & (vi) & (vii) \\
\hline$\Delta$ SHARE $_{t-1}^{30}$ & $\begin{array}{r}-0.360 \\
* * *(0.100)\end{array}$ & $\begin{array}{r}-0.347 \\
* * *(0.106)\end{array}$ & $\begin{array}{r}-0.355 \\
* * *(0.095)\end{array}$ & $\begin{array}{r}-0.387 \\
* * *(0.090)\end{array}$ & $\begin{array}{r}-0.393 \\
* * *(0.089)\end{array}$ & $\begin{array}{r}-0.398 \\
* * *(0.083)\end{array}$ & $\begin{array}{r}-0.392 \\
* * *(0.090)\end{array}$ \\
\hline$\Delta r_{t}^{\text {expost }(30)}$ & $\begin{array}{r}2.709 \\
* * *(0.959)\end{array}$ & & & & $\begin{array}{r}2.716 \\
* * *(0.800)\end{array}$ & $\begin{array}{r}2.516 \\
* * *(0.832)\end{array}$ & $\begin{array}{r}2.706 \\
* * *(0.819)\end{array}$ \\
\hline$\Delta r_{t}^{T R(30)}$ & & $\begin{array}{r}-0.333 \\
(0.731)\end{array}$ & & & & & \\
\hline$\Delta\left|q_{t}-\bar{q}_{t}\right|$ & & & $\begin{array}{r}-0.819 \\
(0.938)\end{array}$ & & & & \\
\hline$\Delta\left(q_{t}-\bar{q}_{t}\right)^{2}$ & & & & $\begin{array}{r}-5.885 \\
* * *(1.969)\end{array}$ & $\begin{array}{r}-5.802 \\
* * *(1.967)\end{array}$ & $\begin{array}{r}-5.865 \\
* * *(1.710)\end{array}$ & $\begin{array}{r}-5.782 \\
* * *(1.910)\end{array}$ \\
\hline$\triangle \mathrm{SHARE}^{P P P}$ & & & & & & $\begin{array}{r}0.547 \\
* *(0.274)\end{array}$ & \\
\hline$\Delta \mathrm{SHARE}^{C T}$ & & & & & & $\begin{array}{r}-0.065 \\
(0.256)\end{array}$ & \\
\hline$\sigma^{(30)}$ & & & & & & & $\begin{array}{r}0.287 \\
(2.288)\end{array}$ \\
\hline const. & $\begin{array}{r}-0.001 \\
(0.008)\end{array}$ & $\begin{array}{r}-0.001 \\
(0.008)\end{array}$ & $\begin{array}{r}-0.000 \\
(0.008)\end{array}$ & $\begin{array}{r}0.000 \\
(0.009)\end{array}$ & $\begin{array}{r}0.000 \\
(0.009)\end{array}$ & $\begin{array}{r}0.001 \\
(0.009)\end{array}$ & $\begin{array}{r}0.000 \\
(0.009) \\
\end{array}$ \\
\hline$T$ & 151 & 151 & 150 & 150 & 150 & 150 & 150 \\
\hline$R^{2}$ & 0.20 & 0.13 & 0.13 & 0.21 & 0.28 & 0.31 & 0.28 \\
\hline adj. $R^{2}$ & 0.19 & 0.12 & 0.12 & 0.20 & 0.27 & 0.28 & 0.26 \\
\hline
\end{tabular}


Table 9: PPP deviations and switching into momentum strategies

Taking the median as the threshold, we distinguish states with high and low deviation of the exchange rate from the PPP-mean-reverting value $\left|q_{t}-\bar{q}_{t}\right|$. In the following, $\Delta \mathrm{SHARE}_{t}^{30}$ denotes the change in the proportion of forecasts made in $t$ which point into the same direction as a trading rule following the trend over the previous 30 days, and $\Delta r_{t}^{\text {expost(30) }}$ denotes the change in the ex-post return of a strategy which has followed the trend of the previous 30 days.

Similarly to the analysis in Table 8, we conduct time series regressions for the states of high or low deviation separately, i.e.,

$$
\Delta \mathrm{SHARE}_{t}^{30}= \begin{cases}a_{01}+a_{11} \Delta \mathrm{SHARE}_{t-1}^{30}+a_{21} \Delta X_{t}+e_{t} & \text { if }\left|q_{t}-\bar{q}_{t}\right|<X_{50}\left(\left|q_{t}-\bar{q}_{t}\right|\right) \\ a_{02}+a_{12} \Delta \mathrm{SHARE}_{t-1}^{30}+a_{22} \Delta X_{t}+e_{t} & \text { if }\left|q_{t}-\bar{q}_{t}\right|>X_{50}\left(\left|q_{t}-\bar{q}_{t}\right|\right)\end{cases}
$$

$\Delta \mathrm{SHARE}_{t-1}^{30}$ is included as lagged dependent variable and $\Delta X_{t}$ represents the changes in the control variables (i.e. $\Delta r_{t}^{\text {expost }(30)}$ and $\Delta\left|q_{t}-\bar{q}_{t}\right|$ ).

Panel A displays the estimates. Due to potential time overlaps (the forecasts are made on a sixmonth horizon, whereas we sample at monthly frequency), we use Newey-West standard errors with a lag length of five months. Standard errors are provided in parentheses. (***: 1\%, **: 5\%, *: $10 \%$ significance level).

\begin{tabular}{|c|c|c|c|c|c|c|}
\hline Panel A & \multicolumn{3}{|c|}{ Lower PPP Deviation } & $\begin{array}{l}\text { High } \\
\text { (iv) }\end{array}$ & $\begin{array}{r}\text { PPP Dev } \\
(\mathrm{v})\end{array}$ & tion \\
\hline$\Delta$ SHARE $_{t-1}^{30}$ & $\begin{array}{r}-0.282 \\
* * *(0.052)\end{array}$ & $\begin{array}{r}-0.310 \\
* * *(0.051)\end{array}$ & $\begin{array}{r}-0.287 \\
* * *(0.058)\end{array}$ & $\begin{array}{r}-0.395 \\
* * *(0.131)\end{array}$ & $\begin{array}{r}-0.457 \\
* * *(0.098)\end{array}$ & $\begin{array}{r}-0.470 \\
* * *(0.090)\end{array}$ \\
\hline$\Delta r_{t}^{\text {expost }(30)}$ & $\begin{array}{r}2.344 \\
* * *(0.734)\end{array}$ & & $\begin{array}{r}2.141 \\
* * *(0.772)\end{array}$ & $\begin{array}{r}3.306 \\
(2.119)\end{array}$ & & $\begin{array}{r}3.110 \\
*(1.566)\end{array}$ \\
\hline$\Delta\left|q_{t}-\bar{q}_{t}\right|$ & & $\begin{array}{r}2.081 \\
* * *(0.540)\end{array}$ & $\begin{array}{r}1.869 \\
* * *(0.445)\end{array}$ & & $\begin{array}{r}-4.352 \\
* * *(1.119)\end{array}$ & $\begin{array}{r}-4.283 \\
* * *(1.135)\end{array}$ \\
\hline const. & $\begin{array}{r}0.002 \\
(0.009)\end{array}$ & $\begin{array}{r}0.006 \\
(0.011)\end{array}$ & $\begin{array}{r}0.007 \\
(0.010)\end{array}$ & $\begin{array}{r}-0.001 \\
(0.013)\end{array}$ & $\begin{array}{r}0.012 \\
(0.015)\end{array}$ & $\begin{array}{r}0.010 \\
(0.015)\end{array}$ \\
\hline$T$ & 74 & 74 & 74 & 75 & 75 & 75 \\
\hline$R^{2}$ & 0.21 & 0.23 & 0.32 & 0.20 & 0.36 & 0.41 \\
\hline adj. $R^{2}$ & 0.19 & 0.21 & 0.29 & 0.18 & 0.34 & 0.38 \\
\hline
\end{tabular}

Panel B shows the mean and standard deviation of $\Delta \mathrm{SHARE}^{30}, \Delta r_{t}^{\operatorname{expost}(30)}$, and $\Delta\left|q_{t}-\bar{q}_{t}\right|$ (i.e. of the monthly changes of the introduced variables) for both states separately.

\begin{tabular}{l|rr|rr|rr}
\hline \hline & \multicolumn{2}{|c|}{ All } & \multicolumn{2}{|c|}{ Lower PPP Deviation } & \multicolumn{2}{|c}{ Higher PPP Deviation } \\
Panel B & Mean & SD & Mean & SD & Mean & SD \\
\hline$\Delta$ SHARE $^{30}$ & -0.0004 & 0.2069 & 0.0014 & 0.1540 & -0.0005 & 0.2500 \\
$\Delta r_{t}^{\text {expost }(30)}$ & 0.0000 & 0.0206 & -0.0006 & 0.0226 & 0.0003 & 0.0184 \\
$\Delta\left|q_{t}-\bar{q}_{t}\right|$ & 0.0004 & 0.0276 & -0.0020 & 0.0284 & -0.0027 & 0.0268 \\
\hline \hline
\end{tabular}


Table 10: Explaining switching into momentum strategies, time series regressions by groups

This table reports the results of a regression of the type described in Table 8. The regressions are conducted separately for chartists and fundamentalists. (***: 1\%, **: 5\%, *: $10 \%$ significance level).

\begin{tabular}{l|rr}
\hline \hline & Fundamentalists & Chartists \\
\hline$\Delta$ SHARE $^{30}$ & -0.385 & -0.488 \\
& $* * *(0.074)$ & $* * *(0.068)$ \\
$\Delta r_{t}^{\text {expost }(30)}$ & 2.232 & 1.846 \\
& $* *(0.873)$ & $* *(0.882)$ \\
$\Delta\left|q_{t}-\bar{q}_{t}\right|$ & & \\
& & \\
$\Delta\left(q_{t}-\bar{q}_{t}\right)^{2}$ & -6.433 & -4.496 \\
& $* * *(1.917)$ & $* *(1.795)$ \\
$\Delta$ SHARE $^{P P P}$ & 0.324 & -0.030 \\
& $*(0.176)$ & $(0.171)$ \\
$\Delta$ SHARE $^{C T}$ & -0.076 & 0.075 \\
& $(0.179)$ & $(0.162)$ \\
const. & 0.002 & 0.001 \\
& $(0.010)$ & $(0.009)$ \\
\hline$T$ & 150 & 150 \\
$R^{2}$ & 0.28 & 0.30 \\
adj. $R^{2}$ & 0.26 & 0.28 \\
\hline \hline
\end{tabular}

Table 11: Performance of trading rules, averages by groups

This table reports the cross-sectional averages (separately for fundamentalists, chartists and intermediates) of the average monthly return (Panel A) and the annualized Sharpe Ratio (Panel B) from trading strategies based on individual forecasts. These trading strategies translate a appreciation (depreciation) expectation into a long (short) position, taken in the forward market; the positions will be closed $k$ months later in the spot market. We consider investments on different horizons, i.e. 1, 2, 3, 6, 12, 24 and 36 months. The last row displays the results of t-statistic, where the $H_{0}$ corresponds to equal means between chartists and fundamentalists. (***: 1\%, **: 5\%, *: $10 \%$ significance level).

\begin{tabular}{l|rrrrrrr}
\hline \hline Panel A: average returns & $1 \mathrm{mo}$ & $2 \mathrm{mo}$ & $3 \mathrm{mo}$ & $6 \mathrm{mo}$ & $12 \mathrm{mo}$ & $24 \mathrm{mo}$ & $36 \mathrm{mo}$ \\
\hline fundamentalists & $0.06 \%$ & $0.07 \%$ & $0.10 \%$ & $0.13 \%$ & $0.08 \%$ & $0.09 \%$ & $0.07 \%$ \\
intermediates & $0.17 \%$ & $0.15 \%$ & $0.12 \%$ & $0.13 \%$ & $0.09 \%$ & $0.11 \%$ & $0.10 \%$ \\
chartists & $0.21 \%$ & $0.18 \%$ & $0.15 \%$ & $0.14 \%$ & $0.09 \%$ & $0.10 \%$ & $0.09 \%$ \\
\hline t-values fund. vs. chart. & $* * 2.34$ & $* 1.81$ & 0.94 & 0.44 & 0.56 & 0.45 & 0.56 \\
\hline \hline Panel B: Sharpe Ratios & $1 \mathrm{mo}$ & $2 \mathrm{mo}$ & $3 \mathrm{mo}$ & $6 \mathrm{mo}$ & $12 \mathrm{mo}$ & $24 \mathrm{mo}$ & $36 \mathrm{mo}$ \\
\hline fundamentalists & 0.06 & 0.11 & 0.14 & 0.20 & 0.10 & 0.16 & 0.17 \\
intermediates & 0.23 & 0.21 & 0.17 & 0.18 & 0.13 & 0.16 & 0.17 \\
chartists & 0.25 & 0.23 & 0.19 & 0.19 & 0.12 & 0.15 & 0.16 \\
\hline t-values fund. vs. chart. & $* * 2.31$ & 1.56 & 0.45 & 0.14 & 0.37 & 0.11 & 0.27 \\
\hline \hline
\end{tabular}


Table 12: Explaining switching into momentum strategies, time series regressions, without autoregressive term

This table reports the results of a regression of the type

$$
\Delta \operatorname{SHARE}_{t}^{30}=a_{0}++a_{1} \Delta X_{t}+e_{t}
$$

where $\triangle \mathrm{SHARE}_{t}^{30}$ denotes the change in the proportion of forecasts made in $t$ which point into the same direction as a trading rule following the trend over the previous 30 days, and $\Delta X_{t}$ represents the changes in several control variables. These control variables include the ex-post return of a strategy which has followed the trend of the previous 30 days, $r_{t}^{\text {expost(30) }}$, the previous month's return of a momentum-strategy chosen on the basis of the trend the month before, $r_{t}^{T R(30)}$, the deviation of the real exchange rate from its moving average of the preceding 10 years, $\left|q_{t}-\bar{q}_{t}\right|$, and the square of this distance, $\left(q_{t}-\bar{q}_{t}\right)^{2}$. In addition, we include $\triangle \mathrm{SHARE}_{t}^{P P P}$ and $\triangle \mathrm{SHARE}_{t}^{C T}$, which denote the change in the proportion of forecasts made in $t$ which point into the same direction as a PPP-oriented (carry-trade oriented) forecast as further control variables. Due to potential time overlaps (the forecasts are made on a six-month horizon, whereas we sample at monthly frequency), we use Newey-West standard errors with a lag length of five months. Standard errors are provided in parentheses. (***: $1 \%, * *: 5 \%, *$ : $10 \%$ significance level).

\begin{tabular}{l|rrrrr}
\hline \hline & (i) & (ii) & (iii) & (iv) & (v) \\
\hline$\Delta r_{t}^{\text {expost }(30)}$ & 2.526 & & & & 2.568 \\
& $* * *(0.868)$ & & & & $* * *(0.745)$ \\
$\Delta r_{t}^{T R(30)}$ & & -0.637 & & & \\
$\Delta\left|q_{t}-\bar{q}_{t}\right|$ & & -0.747 & & & \\
& & & -0.767 & & \\
$\Delta\left(q_{t}-\bar{q}_{t}\right)^{2}$ & & & -0.881 & & \\
& & & & $* * *-5.039$ & $* * *-4.984$ \\
const. & -0.001 & -0.001 & 0.001 & 0.001 & -1.948 \\
& -0.007 & -0.007 & -0.008 & -0.008 & -0.001 \\
\hline$T$ & 151 & 151 & 151 & 151 & 150 \\
$R^{2}$ & 0.06 & 0.01 & 0.01 & 0.06 & 0.13 \\
adj. $R^{2}$ & 0.06 & 0 & 0 & 0.06 & 0.12 \\
\hline \hline
\end{tabular}


Table 13: Performance of trading rules, average absolute forecast errors by groups

This table reports the cross sectional average (for fundamentalists, chartists, and intermediates) of the average absolute forecast errors made by individual forecasters. We compare the forecasts with realized changes on different horizons, i.e., 1, 2, 3, 6, 12, 24, and 36 months. The last row displays the results of t-statistic, where the $H_{0}$ corresponds to equal means between chartists and fundamentalists. (***: $1 \%, * *: 5 \%, *: 10 \%$ significance level).

\begin{tabular}{l|rrrrrrr}
\hline \hline Average absolute forecast error & $1 \mathrm{mo}$ & $2 \mathrm{mo}$ & $3 \mathrm{mo}$ & $6 \mathrm{mo}$ & $12 \mathrm{mo}$ & $24 \mathrm{mo}$ & $36 \mathrm{mo}$ \\
\hline fundamentalists & 0.92 & 0.90 & 0.88 & 0.81 & 0.83 & 0.70 & 0.67 \\
intermediates & 0.88 & 0.87 & 0.86 & 0.84 & 0.83 & 0.74 & 0.71 \\
chartists & 0.87 & 0.86 & 0.86 & 0.82 & 0.81 & 0.75 & 0.71 \\
\hline t-values fund. vs. chart. & ${ }^{* *} 2.10$ & 1.46 & 0.60 & 0.10 & 0.55 & 1.12 & 1.00 \\
\hline \hline
\end{tabular}


Figure 1: Observed momentum-following, depending on size of previous trends

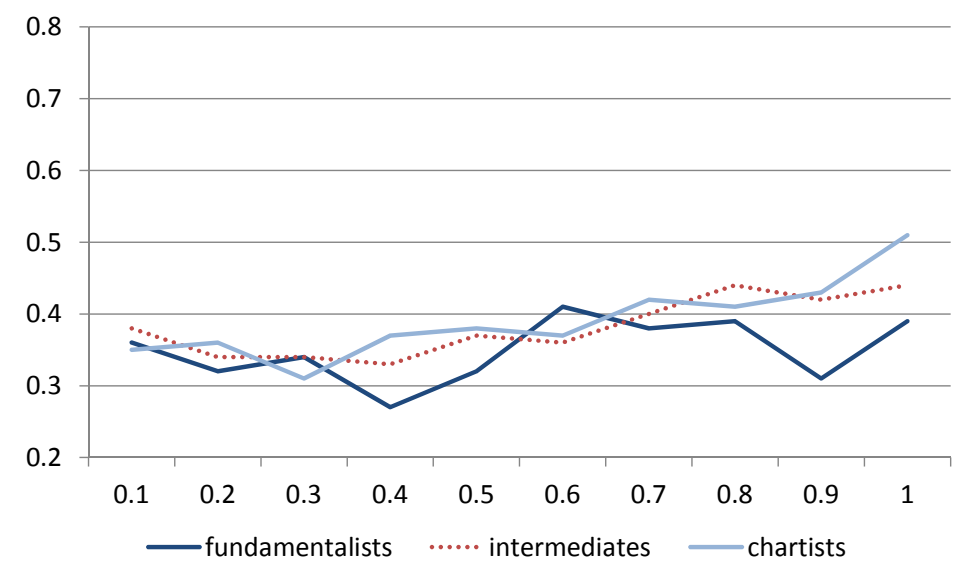

This plot represents a set of cross-sectional averages (for each fundamentalists, chartists, and intermediates separately) of the proportion of individual forecasts which are in line with momentumfollowing behavior (based on the trend observed in the last 30 days). The graph in this figure illustrates the averages in dependence of the market phases, i.e. the absolute size of the trend of the previous 30 days. The $\mathrm{x}$-axis displays the intervals according to deciles $(0.1$ representing the lowest 10 percent of observed trends (0-10\%), 1 representing the highest 10 percent (90-100\%)). The y-axis represents the proportion of forecasts which are in line with momentum strategy (e.g., $0.4=40 \%$ ). The solid dark line represents the group of fundamentalists, the solid light line the group of chartists, and the dotted line the group of intermediates.

Figure 2: Observed PPP-orientation, depending on size of fundamental misalignment

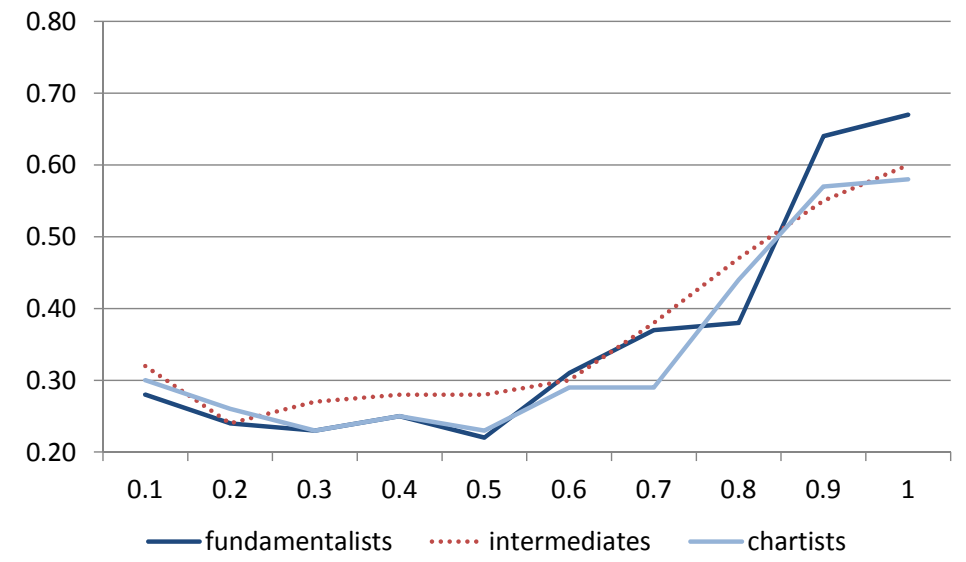

This plot represents a set of cross-sectional averages (for each fundamentalists, chartists, and intermediates separately) of the proportion of individual forecasts which are in line with PPP-oriented behavior (based on the deviation of the real exchange rate from its 10-year moving average). The graph in this figure illustrates the averages in dependence of the market phases, i.e. the absolute deviation. The $\mathrm{x}$-axis displays the intervals according to deciles $(0.1$ representing the lowest 10 percent of observed trends (0-10\%), 1 representing the highest 10 percent (90-100\%)). The y-axis represents the proportion of forecasts which are in line with PPP orientation (e.g., $0.4=40 \%$ ). The solid dark line represents the group of fundamentalists, the solid light line the group of chartists, and the dotted line the group of intermediates. 
Figure 3: Switching probability, illustration

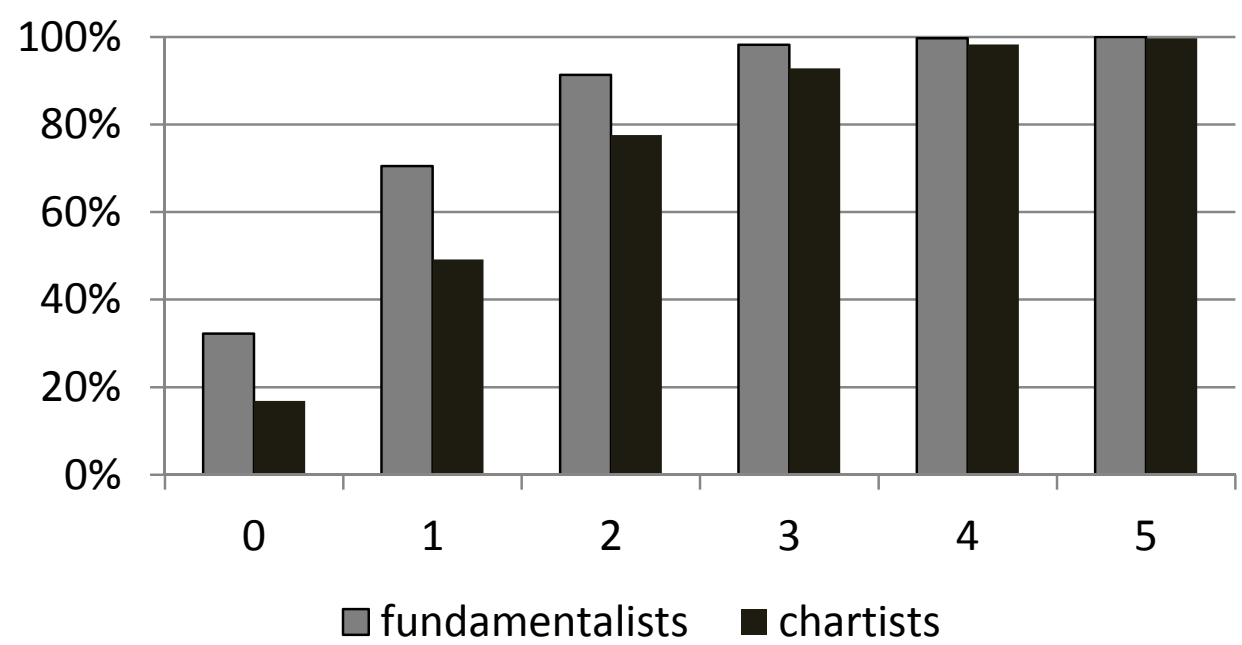

This plot represents the estimated average probability (on the $y$-axis) that fundamentalists and chartists switch the direction of their forecast $x$ times or less over the time span of one year, where $x$ is represented by the $x$-axis.

Figure 4: Proportion of forecasters in line with trend-following behavior

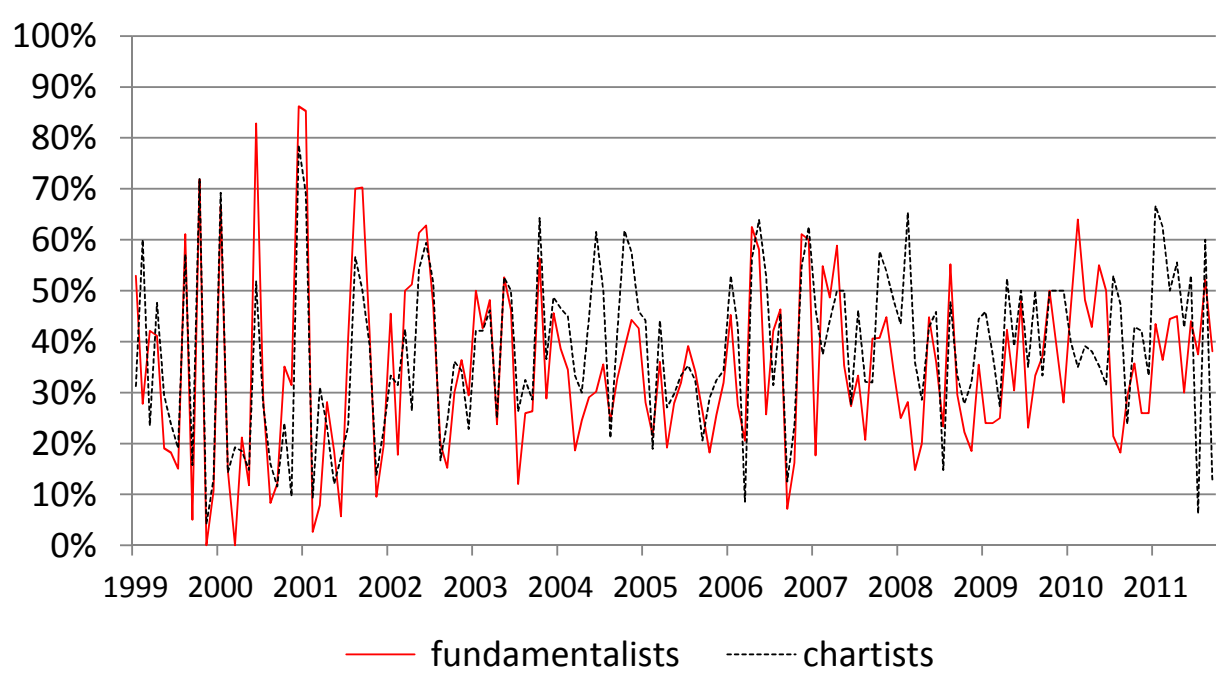

This plot represents the proportion of forecasters whose forecasts are in line with a momentumfollowing strategy which follows the trend of the previous 30 days. The graph plots separate lines for fundamentalists and chartists, respectively. 